\title{
An Improved Stress and Strain Increment Approaches for Circular Tunnel in Strain-Softening Surrounding Rock Considering Seepage Force
}

\author{
Ling Wang $\mathbb{D}^{1,2}$ Jin-feng Zou $\mathbb{D}^{3},{ }^{3}$ and Yu-ming Sheng $\mathbb{D}^{4}$ \\ ${ }^{1}$ Ph.D. Student, School of Civil Engineering, No. 22, Shaoshan South Road, Central South University, Changsha, \\ Hunan 410075, China \\ ${ }^{2}$ Assistant Professor, Design and Art Institute, No. 569, Yuelu Road, Hunan University of Commerce, Changsha, \\ Hunan 410205, China \\ ${ }^{3}$ Professor, School of Civil Engineering, Central South University, No. 22, Shaoshan South Road, \\ Central South University Railway Campus, Changsha, Hunan 410075, China \\ ${ }^{4}$ Ph.D. Student, School of Civil Engineering, Central South University, No. 22, Shaoshan South Road, \\ Central South University Railway Campus, Changsha, Hunan 410075, China \\ Correspondence should be addressed to Yu-ming Sheng; 1916912723@qq.com
}

Received 1 June 2018; Revised 17 November 2018; Accepted 4 February 2019; Published 6 May 2019

Academic Editor: Antonio Boccaccio

Copyright (c) 2019 Ling Wang et al. This is an open access article distributed under the Creative Commons Attribution License, which permits unrestricted use, distribution, and reproduction in any medium, provided the original work is properly cited.

\begin{abstract}
Considering the effect of seepage force, a dimensionless approach was introduced to improve the stress and strain increment approach on the stresses and radial displacement around a circular tunnel excavated in a strain-softening generalized HoekBrown or Mohr-Coulomb rock mass. The circular tunnel can be simplified as axisymmetric problem, and the plastic zone was divided into a finite number of concentric rings which satisfy the equilibrium and compatibility equations. Increments of stresses and strains for each ring were obtained by solving the equilibrium and compatibility equations. Then, the stresses and displacements in softening zone can be calculated. The correctness and reliability of the proposed approach were performed by the existing solutions.
\end{abstract}

\section{Introduction}

Analysis of stresses and displacements around circular tunnel excavated in isotropic rock mass is one of the fundamental problems in geotechnical engineering. A nonlinear method is needed to obtain a reliable solution since the deformation response depends on the stress path. Numerical method, elastoplastic methods, and limit analysis methods are popularly used for cavity expansion or contraction according to the existing literature surveys [1-15]. In the past, Mohr-Coulomb failure criterion was widely used by many scholars for analysis of rock mass. However, experimental observations indicated that the strength envelope for most of rock materials is nonlinear. For the nonlinear failure criterion, the criterion by Hoek and Brown is generally accepted in rock mechanics community, as it can provide a reliable tool for predicting the strength of jointed rock mass. Subsequently, the HoekBrown criterion has been updated to the generalized form and has been widely used. Elastoplastic analysis of circular tunnels excavated in Hoek-Brow and Mohr-Coulomb rock mass was attempted by many scholars [13-16]. For the theoretical analysis, the expressions of stresses and displacements around the tunnel are mainly obtained based on the elastic-perfectly plastic model and elastic-brittleplastic model under the nonassociated flow rule. Park and Kim [13] provided a procedure of strain-softening model for elastoplastic analysis of a circular opening considering elastoplastic coupling. Park et al. [14] presented the variation laws of deformations based on different softening 
indexes and dilatancy characteristics. Sharan [15] provided an analytical solution for stresses and displacements around a circular opening in a generalized Hoek-Brown rock mass. Theoretical formulation and solutions for poorly consolidated rocks surrounding a circular opening are presented by Wang [16]. Han et al. [17] analyzed variation regulations of the stresses and deformation around the tunnel for elastic-brittle-plastic behavior considering the load-bearing characteristics of the plastic zone. However, the variation laws of the stresses and deformation around the tunnel excavated in a strain-softening rock mass were studied by numerical analysis. Zheng et al. [18] pointed out that the convergent problem was existed in the finite-element analysis of strain-softening rock mass with a higher softening rate. Therefore, the plastic zone of a circular tunnel may be divided into many zones to be analyzed generally. For example, Brown et al. [2] thought that the elastic deformation of rock mass is a constant value; then, the stresses and displacement field can be calculated easily. Wang et al. $[19,20]$ presented an analytical approximation solution for a circular opening in an elasto-brittle-plastic rock. Lee and Pietruszczak [21] provided a new numerical procedure for elastoplastic analysis of a circular opening excavated in a strain-softening rock mass by using the difference method.

It can be seen from the researches worldwide that the theoretical analysis method and numerical simulation are two main techniques for analysis of strain-softening rock mass. The theoretical approaches can reflect the innate character of strain-softening rock mass, but the parameters for calculation which are usually not consistent with the actual values may cause computational errors as well. The numerical simulation shows the development of the softening rock mass. However, there exists some error in the solutions compared with the theoretical values. In the recent reports about the elastoplastic analysis of a circular opening excavated in a strain-softening rock mass, it is unusual to find a solution considering both the axial stress and seepage force in practical engineering. But the axial stress and seepage force have obvious influence on the surrounding rock's stability, especially in strain-softening rock mass. And most diseases are related to the seepage force directly or indirectly. Only analyzing the influence of axial stress on the stresses and displacement of circular tunnel without considering seepage force does not accord with the practical engineering at abundant area. Therefore, the seepage fore is of great important for softening rock mass.

Therefore, on the basis of theoretical analysis, the dimensionless method is introduced in this study to eliminate the influence on the dimensions of variables and parameters based on the generalized Hoek-Brown and M-C failure criterion. Simultaneously, both the axial stress and seepage force are considered for reconstruction of the stepstress approach to analyze the strain-softening rock mass. Then, a new dimensionless method for the elastoplastic analysis of a circular opening excavated in a strain-softening rock mass considering seepage force is established in this study, which in hope of providing theoretical supports for the digging process and design of tunnel in a strainsoftening rock mass.

The innovations of this study are listed as follows:

(1) The dimensionless method pointed out by CarranzaTorres and Fairhurst [22] is only applicable to the original Hoek-Brown rock mass. However, the dimensionless solutions in this study are based on the generalized Hoek-Brow and M-C rock mass. Thus, the dimensionless method of Carranza-Torres and Fairhurst [22] is a special case of that in this study, and the dimensionless method in this study is the expansion and extension of that of Carranza-Torres and Fairhurst [22].

(2) Not only the generalized Hoek-Brown and M-C failure criteria but also the seepage force is considered in this study, and a new dimensionless method for analysis of the circular opening excavated in a strain-softening rock mass is presented, which is rarely studied from the existing literatures.

(3) The dimensionless method pointed out by CarranzaTorres and Fairhurst [22] is only suitable for the elastoplastic rock mass. However, the dimensionless method in this study is used in strain-softening rock mass and can also be simplified for the elastic-brittleplastic and elastoplastic rock mass, which means the dimensionless method in Carranza-Torres and Fairhurst [22] is a special case of that in this study, and the dimensionless method in this study is the expansion and extension of that in Carranza-Torres and Fairhurst [22].

\section{Definition of Problem}

Figure 1 illustrates that a circular tunnel with radius $b$ is imposed by a stress field $\sigma_{0}$ throughout the domain before the tunnel is excavated. As the internal support pressure $p_{i}$ is less than the critical value $p_{i c}$, a plastic zone is formed around the circular tunnel. Plastic radius can be derived for the elasticbrittle-plastic or elastic-perfectly plastic behavior [23, 24]. Furthermore, when considering the strain-softening behavior, the plastic zone can be divided into softening and residual zones whose interface is expressed by $R_{S}$ in Figure 1. However, it is difficult to obtain a closed-form solution for strain-softening rock mass, and the distributions for stresses and displacement should be solved by numerical method.

2.1. Yield Function. Assuming that the yielding of the rock mass is governed by the function,

$$
F\left(\sigma_{\theta}, \sigma_{r}, \gamma^{p}\right)=\sigma_{\theta}-\sigma_{r}-H\left(\sigma_{r}, \gamma^{p}\right),
$$

where $\sigma_{\theta}$ and $\sigma_{r}$ are the major principal stress and minor principal stress, respectively, and $\gamma^{p}$ is the strain-softening parameter which reflects the evolution of the strength parameters in strain-softening rock mass and can be expressed as follows:

$$
\gamma^{p}=\gamma_{\theta}^{p}-\gamma_{r}^{p}
$$




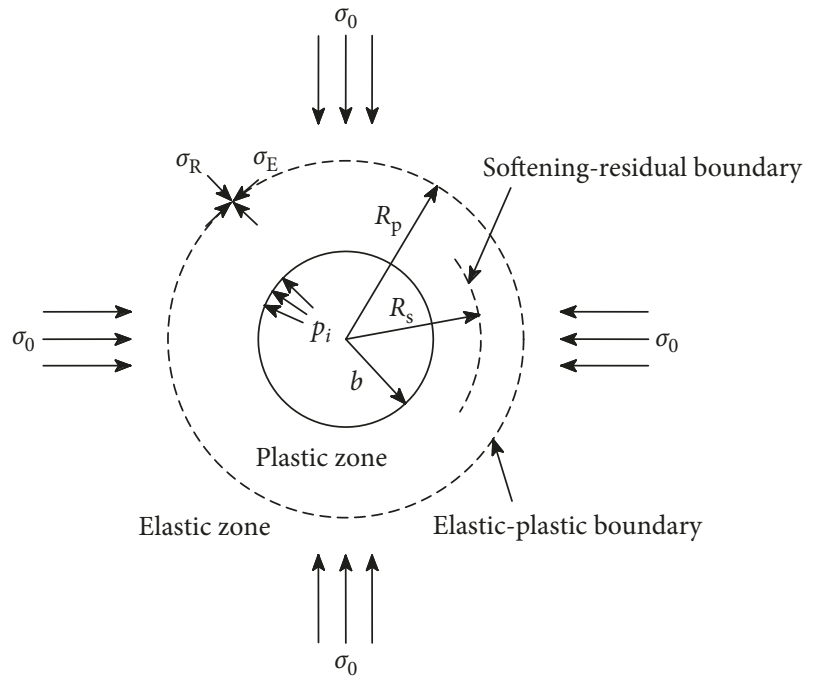

Figure 1: Plastic zone formed around circular opening.

Alonso et al. [1] pointed out that no universal method was available to define the strain-softening parameter, but the definition in Equation (2) is widely accepted now.

For the $\mathrm{M}-\mathrm{C}$ rock mass,

$$
H\left(\sigma_{r}, \gamma^{p}\right)=\left(N\left(\gamma^{p}\right)-1\right) \sigma_{r}+Y\left(\gamma^{p}\right),
$$

where $N$ and $Y$ are respectively strength parameters defined according to the friction angle $\phi\left(\gamma^{p}\right)$ and cohesion $c\left(\gamma^{p}\right)$ :

$$
\begin{aligned}
& N\left(\gamma^{p}\right)=\frac{1+\sin \phi\left(\gamma^{p}\right)}{1-\sin \phi\left(\gamma^{p}\right)}, \\
& Y\left(\gamma^{p}\right)=\frac{2 c\left(\gamma^{p}\right) \cos \phi\left(\gamma^{p}\right)}{1-\sin \phi\left(\gamma^{p}\right)} .
\end{aligned}
$$

For the generalized H-B rock mass,

$$
H^{\mathrm{HB}}\left(\sigma_{r}, \gamma^{p}\right)=\sigma_{\mathrm{c}}\left(\gamma^{p}\right)\left(m\left(\gamma^{p}\right) \frac{\sigma_{r}}{\sigma_{\mathrm{c}}\left(\gamma^{p}\right)}+s\left(\gamma^{p}\right)\right)^{a\left(\gamma^{p}\right)},
$$

where $\sigma_{c}$ is the uniaxial compressive strength of rock and $m$, $s$, and $a$ are also the strength parameters for the H-B surrounding rock.

2.2. Plastic Potential Function. The $\mathrm{M}-\mathrm{C}$ criterion is regarded as the plastic potential function, and it may be written as follows:

$$
G\left(\sigma_{\theta}, \sigma_{r}, \gamma^{p}\right)=\sigma_{\theta}-k\left(\gamma^{p}\right) \sigma_{r},
$$

where $k\left(\gamma^{p}\right)$ is the coefficient of dilation and may be written as follows:

$$
k\left(\gamma^{p}\right)=\frac{1+\sin \varphi\left(\gamma^{p}\right)}{1-\sin \varphi\left(\gamma^{p}\right)}
$$

where $\varphi$ is the angle of dilation, and when $\varphi$ is equal to internal frictional angle $\phi$, the plastic flow rule is related. When $k\left(\gamma^{p}\right)=1.0$, no plastic volume change occurs.
Therefore, the relationship between the radial and circumferential plastic strain increments can be obtained based on the plastic flow rule:

$$
d \varepsilon_{r}^{p}=-k\left(\gamma^{p}\right) d \varepsilon_{\theta}^{p}
$$

2.3. Evolution of Strength Parameters. The strength and deformation parameters presented in Equations (3), (5), and (6) are functions of $\gamma^{p}$. In plastic regime, these parameters can be described by bilinear functions of deviatoric plastic strain $\gamma^{p}$, which are shown in the following equation:

$$
\omega\left(\gamma^{p}\right)= \begin{cases}\omega_{p}-\left(\omega_{r}-\omega_{p}\right) \frac{\gamma^{p}}{\gamma^{p *}}, & 0<\gamma^{p}<\gamma^{p *}, \\ \omega_{r}, & \gamma^{p} \geq \gamma^{p *},\end{cases}
$$

where $\omega$ denotes one of the parameters $\phi, c, \sigma_{c}, m, s, \varphi$, and $a$, and $\gamma^{p *}$ is the critical deviatoric plastic strain from which the residual behavior is firstly observed. The value of $\gamma^{p *}$ should be identified by experiments. This linear deterioration process of strength parameters is illustrated in Figure 2, where the subscripts $p$ and $r$ represent the peak and residual values of strength and deformation parameters, respectively.

2.4. Critical Supporting Pressure. When the internal support pressure $p_{i}$ is lower than $p_{i c}$, the plastic zone develops. For $\mathrm{M}-\mathrm{C}$ rock mass, $p_{i c}$ can be calculated by the following equation:

$$
p_{i c}^{\mathrm{MC}}=\frac{2 \sigma_{0}-Y_{p}}{N_{p}+1},
$$

where $Y_{p}=2 c_{p} \cos \phi_{p} /\left(1-\sin \phi_{p}\right)$ and $N_{p}=\left(1+\sin \phi_{p}\right) /$ $\left(1-\sin \phi_{p}\right)$.

For $\mathrm{H}-\mathrm{B}$ rock mass, $p_{i c}$ can be obtained by solving the following nonlinear equation:

$$
2\left(\sigma_{0}-p_{i c}\right)=\sigma_{c p}\left(m_{p} \frac{p_{i c}}{\sigma_{c p}}+s_{p}\right)^{a_{p}} .
$$

When $a=0.5, p_{i c}$ is expressed as follows:

$$
p_{i c}^{\mathrm{HB}}=\frac{1}{2}\left(\beta-\sqrt{\beta^{2}+4 \beta \sigma_{0}+s \sigma_{c p}^{2}}\right)+\sigma_{0},
$$

where $\beta=\left(m p \sigma_{c p}\right) / 4$.

If $a>0.5, p_{i c}^{\mathrm{HB}}$ can be calculated numerically based on suitable root-finding algorithm, such as Newton-Raphson method.

When the plastic zone is formed, radial stress $\sigma_{R}$ is equal to $p_{i c}$ on the elastic-plastic interface and $\sigma_{R}$ is independent of radius $r$ :

$$
\sigma_{R}=\sigma_{r}\left(R_{p}\right)=p_{i c}
$$

\section{Approximation of Strain-Softening Behavior}

3.1. Preliminaries. The plastic zone can be divided into $n$ concentric annuli, and the $i$ th annulus is bounded by two 


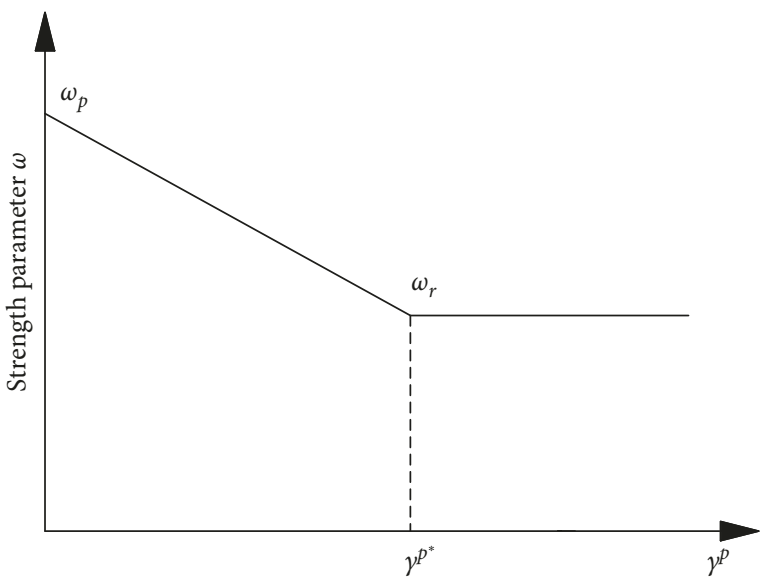

FIGURE 2: Evolution of parameters in plastic regime.

circles of normalized radii $r_{(i-1)}=R_{(i-1)} / R_{p}$ and $r_{(i)}=R_{(i)} / R_{p}$ in Figure 3. The thickness of each annulus is not uniform in general. On the outer boundary of plastic zone, where $r_{(0)}=1$, stress and strain components under plane strain condition are obtained from Equations (14) and (15).

$$
\begin{aligned}
& \left\{\begin{array}{c}
\sigma_{r(0)} \\
\sigma_{\theta(0)}
\end{array}\right\}=\left\{\begin{array}{c}
\sigma_{R} \\
2 \sigma_{0}-\sigma_{R}
\end{array}\right\}, \\
& \left\{\begin{array}{c}
\varepsilon_{r(0)} \\
\varepsilon_{\theta(0)}
\end{array}\right\}=\frac{1+v}{E}\left\{\begin{array}{c}
\sigma_{R}-\sigma_{0} \\
\sigma_{0}-\sigma_{R}
\end{array}\right\} .
\end{aligned}
$$

3.2. Increments of Stresses and Elastic Strains. A dimensionless method is proposed for calculating the increments of stresses and elastic strains. The circular tunnel can be simplified as axisymmetric problem, and the plastic zone is divided into a finite number of concentric rings which satisfy the equilibrium and compatibility equations in strain-softening rock mass. The increments of stresses and strains for each ring are obtained by solving the equilibrium and compatibility equations. Then, the stresses and displacements in the softening zone can be calculated.

Define a dimensionless variable $\rho$, which maps the physical plane $(r, \xi)$ into a plane of coordinate $\rho$ based on the following transformation:

$$
\rho=\frac{r}{b \xi}
$$

Then, the plastic zone can be translated into a unit plane. In the unit plane, the position of the elastic-plastic interface is fixed by $\rho=1$, and the wall of the cavity is defined by $\rho=1 / \xi$.

In order to simplify the calculation process, the forms of the generalized Hoek-Brown and Mohr-Coulomb criteria need to be translated into the dimensionless forms which are in the same order of magnitude in this study. The yield function is expressed as follows:

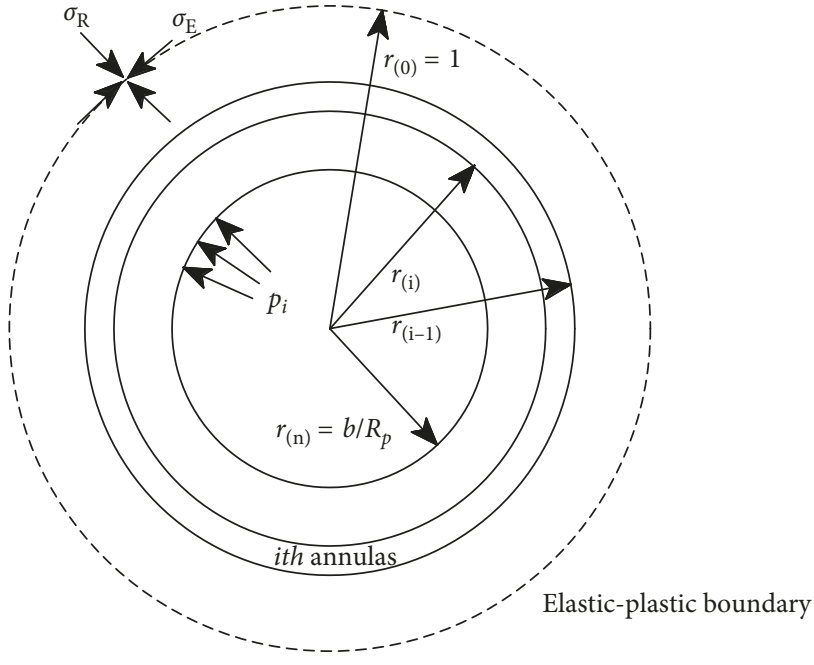

FIgURE 3: Normalized plastic zone with finite number of annuli.

$$
f\left(\sigma_{\theta}, \sigma_{r}\right)=\sigma_{\theta}-\sigma_{r}-H\left(\sigma_{r}, \gamma^{p}\right)=0 .
$$

For the Hoek-Brown criterion, the transformed radial and tangential stresses are expressed as follows:

$$
\left\{\begin{array}{l}
S_{\theta}=\frac{\sigma_{\theta}}{m_{b} \sigma_{c i}}+\frac{s}{m_{b}^{2}}, \\
S_{r}=\frac{\sigma_{r}}{m_{b} \sigma_{c i}}+\frac{s}{m_{b}^{2}} .
\end{array}\right.
$$

The transformed internal pressure and far-field stress are

$$
\left\{\begin{array}{l}
P_{i}=\frac{p_{i}}{m_{b} \sigma_{c i}}+\frac{s}{m_{b}^{2}}, \\
S_{0}=\frac{\sigma_{0}}{m_{b} \sigma_{c i}}+\frac{s}{m_{b}^{2}} .
\end{array}\right.
$$

In order to be consistent with the definition of elastic strain rates, shear modulus can be scaled according to the following expression:

$$
\gamma=\frac{G}{m_{b} \sigma_{c i}} .
$$

Then, the yield function for the generalized HoekBrown criteria may be rewritten by

$$
f\left(S_{\theta}, S_{r}\right)=S_{\theta}-S_{r}-m_{b}^{2 a-1}\left(S_{r}\right)^{a}=0 .
$$

For the $\mathrm{M}-\mathrm{C}$ criterion, the transformed radial and tangential stresses are given by

$$
\left\{\begin{array}{l}
S_{\theta}=\frac{\sigma_{\theta}}{N-1}, \\
S_{r}=\frac{\sigma_{r}}{N-1} .
\end{array}\right.
$$


And the transformed internal pressure and far-field stress are

$$
\left\{\begin{array}{l}
P_{i}=\frac{P_{i}}{N-1}, \\
S_{0}=\frac{\sigma_{0}}{N-1} .
\end{array}\right.
$$

Then, the yield function for the Mohr-Coulomb criteria can be rewritten as follows:

$$
f\left(S_{\theta}, S_{r}\right)=S_{\theta}+N S_{r}+\frac{Y}{N-1}=0 .
$$

Based on the dimensionless method in Carranza-Torres and Fairhurst [22], the stress magnitude, $\sigma_{0}-\sigma_{r}^{*}$, is used to normalize the stresses by

$$
\left\{\begin{array}{l}
\widetilde{S}_{\theta}=\frac{S_{\theta}}{S_{0}-S_{r}^{*}}, \\
\widetilde{S}_{r}=\frac{S_{r}}{S_{0}-S_{r}^{*}} .
\end{array}\right.
$$

Based on the method pointed out by Brown et al. [2], radial stresses in the plastic zone may be divided into $n$ parts, and the increments of radial stress can be expressed as follows:

$$
\Delta \sigma_{r}=\frac{p_{i}-\sigma_{0}}{n}
$$

According to Equation (23), and Equation (26) can be written as follows:

$$
\Delta \widetilde{S}_{r}=\frac{P_{i}-S_{0}}{n}
$$

And the stress components for the $i$ th annulus can be given as follows:

$$
\widetilde{S}_{r(i)}=\widetilde{S}_{r(i-1)}+\Delta \widetilde{S}_{r}
$$

In fact, if $n$ is sufficiently large, the circumferential stress can be written as follows:

$$
\widetilde{S}_{\theta(i)}=\widetilde{S}_{r(i)}+H\left(\widetilde{S}_{r(i)}, \gamma_{(i-1)}^{p}\right)
$$

3.3. Approximation of Displacements. When the number of annuli $n$ is sufficiently large and assuming that the strength parameters of rock mass is kept constant in each centric annulus, equilibrium equation can be transformed into

$$
\frac{d \sigma_{r}}{d r}+\frac{\sigma_{r}-\sigma_{\theta}}{r}=0
$$

According to the transformation in Equation (25), the partial derivatives of the field functions with respect to the variables $r$ and $\xi$ are evaluated with the following operators:

$$
\frac{\partial()}{\partial r}=\frac{1}{b \xi} \frac{d()}{d \rho},
$$

$$
\frac{\partial()}{\partial \xi}=\frac{\rho}{\xi} \frac{d()}{d \rho}
$$

In the unit plane, the equilibrium condition may be written as

$$
\frac{d \widetilde{S}_{r}}{d \rho}+\frac{\widetilde{S}_{r}-\widetilde{S}_{\theta}}{\rho}=0,
$$

or

$$
\frac{d \widetilde{S}_{r}}{d \rho}+\frac{H\left(\widetilde{S}_{r(i)}, \gamma_{(i-1)}^{p}\right)}{\rho}=0 .
$$

Equation (34) can be approximated for the $i$ th annulus as

$$
\frac{\widetilde{S}_{r(i)}-\widetilde{S}_{r(i-1)}}{\rho_{(i)}-\rho_{(i-1)}}+\frac{H\left(\overline{\tilde{S}}_{r(i)}, \gamma_{(i-1)}^{p}\right)}{\rho_{(i)}-\rho_{(i-1)}}=0,
$$

where $\overline{\widetilde{S}}_{r(i)}=\left(\widetilde{S}_{r(i)}+\widetilde{S}_{r(i-1)}\right) / 2$. Then, the inner radius can be obtained as follows:

$$
\rho_{(i)}=\frac{2 H\left(\overline{\widetilde{S}}_{r(i)}, \gamma_{(i-1)}^{p}\right)+\Delta \widetilde{S}_{r}}{2 H\left(\overline{\widetilde{S}}_{r(i)}, \gamma_{(i-1)}^{p}\right)-\Delta \widetilde{S}_{r}} \rho_{(i-1)} .
$$

To solve the plastic strain increments, the displacement compatibility equation is considered:

$$
\frac{d \varepsilon_{\theta}}{d r}+\frac{\varepsilon_{\theta}-\varepsilon_{r}}{r}=0
$$

In order to work with dimensionless field quantities, the strains may be normalized as follows:

$$
\begin{aligned}
& \widetilde{\varepsilon}_{\theta}=\frac{2 \gamma}{\left(S_{0}-S_{r}^{*}\right)} \varepsilon_{\theta}, \\
& \widetilde{\varepsilon}_{r}=\frac{2 \gamma}{\left(S_{0}-S_{r}^{*}\right)} \varepsilon_{r} .
\end{aligned}
$$

So that the displacement compatibility equation can be written as follows:

$$
\frac{d \widetilde{\varepsilon}_{\theta}}{d \rho}+\frac{\widetilde{\varepsilon}_{\theta}-\widetilde{\varepsilon}_{r}}{\rho}=0
$$

In the plastic zone, the total strains can be decomposed into elastic and plastic parts as follows:

$$
\left\{\begin{array}{c}
\widetilde{\varepsilon}_{r} \\
\widetilde{\varepsilon}_{\theta}
\end{array}\right\}=\left\{\begin{array}{c}
\widetilde{\varepsilon}_{r}^{e} \\
\widetilde{\varepsilon}_{\theta}^{e}
\end{array}\right\}+\left\{\begin{array}{c}
\widetilde{\varepsilon}_{r}^{p} \\
\widetilde{\varepsilon}_{\theta}^{p}
\end{array}\right\} .
$$

Equation (38) may be reformulated as

$$
\frac{d \widetilde{\varepsilon}_{\theta}^{p}}{d \rho}+\frac{\widetilde{\varepsilon}_{\theta}^{p}-\widetilde{\varepsilon}_{r}^{p}}{\rho}=-\frac{d \widetilde{\varepsilon}_{\theta}^{e}}{d \rho}-\frac{\widetilde{\varepsilon}_{\theta}^{e}-\widetilde{\varepsilon}_{r}^{e}}{\rho} .
$$

Then,

$$
\frac{d \widetilde{\varepsilon}_{\theta}^{p}}{d \rho}+\frac{\widetilde{\mathcal{\varepsilon}}_{\theta}^{p}-\widetilde{\varepsilon}_{r}^{p}}{\rho}=-\frac{d \widetilde{\varepsilon}_{\theta}^{e}}{d \rho}-\frac{\widetilde{\mathcal{\varepsilon}}_{\theta}^{e}-\widetilde{\varepsilon}_{r}^{e}}{\rho} .
$$


According to Hooke's law, under the plane strain condition,

$$
\left\{\begin{array}{c}
\Delta \varepsilon_{r(i)} \\
\Delta \varepsilon_{\theta(i)}
\end{array}\right\}=\frac{1+v}{E}\left[\begin{array}{cc}
1-v & -v \\
-v & 1-v
\end{array}\right]\left\{\begin{array}{c}
\Delta \sigma_{r(i)} \\
\Delta \sigma_{\theta(i)}
\end{array}\right\} .
$$

So, Equation (43) may be reformulated as follows:

$$
\left\{\begin{array}{c}
\Delta \widetilde{\mathcal{E}}_{r(i)} \\
\Delta \widetilde{\mathcal{E}}_{\theta(i)}
\end{array}\right\}=\frac{2 \gamma(1+v)}{E}\left[\begin{array}{cc}
1-v & -v \\
-v & 1-v
\end{array}\right]\left\{\begin{array}{c}
\Delta \widetilde{S}_{r(i)} \\
\Delta \widetilde{S}_{\theta(i)}
\end{array}\right\} .
$$

Combining Equations (36), (42), and (44), the following equation can be obtained:

$$
\begin{aligned}
& \left(\frac{1}{\Delta \rho_{(i)}}+\left(1+k_{(i-1)}\right) \frac{1}{\bar{\rho}_{(i)}}\right) \Delta \widetilde{\varepsilon}_{\theta(i)}^{p} \\
& =-\frac{\Delta \widetilde{\varepsilon}_{\theta(i)}^{e}}{\Delta \rho_{(i)}}-\frac{2 \gamma(1+v)}{E} \frac{H\left(\overline{\widetilde{S}}_{r(i)}, \gamma_{(i-1)}^{p}\right)}{\bar{\rho}_{(i)}} \\
& -\frac{1}{\bar{\rho}_{(i)}}\left(\widetilde{\varepsilon}_{\theta(i-1)}^{p}-\widetilde{\varepsilon}_{r(i-1)}^{p}\right),
\end{aligned}
$$

where $\bar{\rho}_{(i)}=\left(\bar{\rho}_{(i-1)}+\bar{\rho}_{(i)}\right) / 2$ and $k_{(i-1)}=\left(1+\sin \varphi_{(i-1)}\right) /$ $\left(1-\sin \varphi_{(i-1)}\right)$. The deviatoric plastic shear strain is updated as follows:

$$
\gamma_{(i)}^{p}=\gamma_{(i-1)}^{p}+\left(\Delta \widetilde{\varepsilon}_{\theta(i)}^{p}-\Delta \widetilde{\varepsilon}_{r(i)}^{p}\right) .
$$

The total strain at the $i$ th annulus can be given by

$$
\left\{\begin{array}{c}
\widetilde{\varepsilon}_{r(i)} \\
\widetilde{\varepsilon}_{\theta(i)}
\end{array}\right\}=\left\{\begin{array}{c}
\widetilde{\varepsilon}_{r(i-1)} \\
\widetilde{\varepsilon}_{\theta(i-1)}
\end{array}\right\}+\left\{\begin{array}{c}
\Delta \widetilde{\varepsilon}_{r(i)}^{e} \\
\Delta \widetilde{\varepsilon}_{\theta(i)}^{e}
\end{array}\right\}+\left\{\begin{array}{c}
\Delta \widetilde{\varepsilon}_{r(i)}^{p} \\
\Delta \widetilde{\varepsilon}_{\theta(i)}^{p}
\end{array}\right\} .
$$

Recalling the relationship,

$$
\begin{aligned}
\tilde{u} & =\frac{2 \gamma}{b\left(S_{0}-S_{r}^{*}\right)} u_{r}, \\
\widetilde{\varepsilon}_{\theta} & =\frac{2 \gamma}{\left(S_{0}-S_{r}^{*}\right)} \varepsilon_{\theta}, \\
\varepsilon_{\theta} & =\frac{u}{R},
\end{aligned}
$$

then,

$$
\widetilde{\varepsilon}_{\theta}=\frac{\widetilde{u} b}{R}=\frac{\widetilde{u}}{\rho \xi R_{p}} .
$$

Then, the displacement normalized by plastic radius $R_{p}$ can be obtained as follows:

$$
\widetilde{U}_{(i)}=\widetilde{\varepsilon}_{\theta(i)} r_{(i)}=\widetilde{\varepsilon}_{\theta(i)} \rho_{(i)} \xi,
$$

where $\widetilde{U}_{(i)}=\widetilde{u}_{(i)} / R_{p}$.

By using the dimensionless method, the stresses and displacements in the softening zone can be calculated. The actual value of displacement can be calculated by the following equation:

$$
u_{r}=\frac{b\left(S_{0}-S_{r}^{*}\right)}{2 \gamma} \widetilde{u} .
$$

The plastic radius $R_{p}$ can be calculated from the following formula:

$$
R_{p}=\frac{b}{r_{(n)}}=\frac{1}{\rho_{(n)} \xi}
$$

\section{Verification Examples}

4.1. Verifications for $H-B$ and $M-C$ Rock Mass. In order to verify the correctness of the dimensionless solutions, the generalized Hoek-Brown criterion is firstly considered in this study. It is obvious that the strain-softening solutions converge to the brittle-plastic solutions when the critical deviatoric plastic strain $\gamma^{p *}$ is equal to 0 . However, the elastic-brittle-plastic case, $\gamma^{p *}=0$, is the special case of strain-softening behavior. Comparing with the exact solutions for elastic-brittle-plastic rock mass, the dimensionless solutions can be verified.

The stresses and displacement obtained by Sharan [15] are compared with the results in this study, and the equations given by Sharan [15] are obtained from the following equations:

$$
\sigma_{r}=p_{0}+\frac{1}{4} m_{b} \sigma_{c i}\left[\ln \left(\frac{r}{a}\right)\right]^{2}+\left[\ln \left(\frac{r}{a}\right)\right] \sqrt{m_{b} \sigma_{c i} p_{0}+s_{r} \sigma_{c i}^{2}},
$$

$$
\begin{aligned}
\sigma_{\theta} & =\sigma_{r}+\sqrt{m_{b} \sigma_{c i} \sigma_{r}+s_{r} \sigma_{c i}^{2}}, \\
u & =\frac{1}{r}\left[\left(\frac{1+v}{E}\right)\left(\sigma_{R}-\sigma_{0}\right)+\int_{r}^{R} r\left(\varepsilon_{r}+\varepsilon_{\theta}\right) d_{r}\right] .
\end{aligned}
$$

According to the dimensionless method, compared with the results in this study in the same order of magnitude, Equations (53)-(55) can be normalized as follows:

$$
\widetilde{S}_{r}=\frac{1}{\left(S_{0}-S_{r}^{*}\right)}\left\{P_{0}+\frac{1}{4}[\ln (\rho \xi)]^{2}+[\ln (\rho \xi)] \sqrt{P_{0}}\right\},
$$

$$
\widetilde{S}_{\theta}=\widetilde{S}_{r}+\frac{\sqrt{P_{0}}}{\left(S_{0}-S_{r}^{*}\right)},
$$

$$
\widetilde{u}=\frac{2 \gamma}{r b\left(S_{0}-S_{r}^{*}\right)}\left[\left(\frac{1+v}{E}\right)\left(\sigma_{R}-\sigma_{0}\right)+\int_{r}^{R} r\left(\varepsilon_{r}+\varepsilon_{\theta}\right) d_{r}\right] .
$$

In addition, compared with the results based on the generalized $\mathrm{H}-\mathrm{B}$ and $\mathrm{M}-\mathrm{C}$ failure criteria, the technique of equivalent $\mathrm{M}-\mathrm{C}$ and generalized $\mathrm{H}-\mathrm{B}$ strength parameters was adopted for the comparison between the developed method and the exact solutions in Sharan [15]. The 
equations for the friction angle $(\phi)$ and cohesive $(i)$ are given by Yang and Pan [25]:

$$
\begin{aligned}
& \phi=\sin ^{-1}\left[\frac{6 a m_{b}\left(s+m_{b} \sigma_{3 n}\right)^{a-1}}{2(1+a)(2+a)+6 a m_{b}\left(s+m_{b} \sigma_{3 n}\right)^{a-1}}\right], \\
& c=\frac{\sigma_{c i}\left[(1+2 a) s+(1-a) m_{b} \sigma_{3 n}\right]\left(s+m_{b} \sigma_{3 n}\right)^{a-1}}{(1+a)(2+a) \sqrt{1+\left(6 a m_{b}\left(s+m_{b} \sigma_{3 n}\right)^{a-1}\right) /((1+a)(2+a))}},
\end{aligned}
$$

where $\sigma_{3 n}=\sigma_{3 \max } / \sigma_{c i}, \quad\left(\sigma_{3 \max } / \sigma_{c m}\right)=0.47\left(\sigma_{c m} / \gamma H\right)^{-0.94}$, $\sigma_{c m}=\sigma_{c i}\left(\left(m_{b}+4 s-a\left(m_{b}-8 s\right)\right)\left(\left(m_{b} / 4\right)+s\right)^{a-1}\right) / 2(1+a)$ $+a), \sigma_{c m}$ is the rock mass strength, $\gamma$ is the unit weight of the rock mass, and $H$ is the depth of the tunnel below the surface.

The above formulas can be used to transfer the parameters from the $\mathrm{H}-\mathrm{B}$ yield criterion to $\mathrm{M}-\mathrm{C}$ yield criterion. But that may create some errors in practical calculations.

The data sets appearing in Sharan [15] were chosen as input parameters for calculation in this study: $b=5 \mathrm{~m}, \sigma_{0}=30 \mathrm{MPa}$, $p_{i}=5 \mathrm{MPa}, \quad E=5 \mathrm{GPa}, \quad v=0.25, \quad \sigma_{c p}=\sigma_{c r}=30 \mathrm{MPa}$, $m_{p}=1.7, s_{p}=0.0039, m_{r}=1.0, s_{r}=0.0$, and $a_{p}=a_{r}=0.5$. And two dilation angles, $\varphi_{r}=0^{\circ}$ and $30^{\circ}$, were used to evaluate the influence of plastic volume change.

Stresses and displacements in this study can be obtained by writing a program at the case of $\gamma^{p}=0$. Then, based on Equations (56)-(58), the elastic-brittle-plastic solutions and exact solutions can be compared. The results are shown in Figures 4 and 5.

Figure 4 shows the comparison between dimensionless solutions and exact solutions for Hoek-Brown rock mass. The ordinate $S$ stands for the dimensionless stresses.

From Figure 4, when the number of annuli $n=500$, the distributions of radial and circumferential stresses match the exact solutions well, which validate the accuracy of the dimensionless solutions. Figure 5 gives the comparison between dimensionless displacement and exact displacement for Hoek-Brown rock mass. As can be seen in Figure 5, the distribution of radial displacement obtained by the proposed approach shows a good agreement with the exact solution. So, the dimensionless solutions prove to be accurate.

Figures 6 and 7 show the distribution of errors between dimensionless solutions and exact solutions. The abscissa denotes $\rho \xi$. The ordinate stands for the error percentage between dimensionless solutions and exact solutions. Moreover, in order to examine the influence of mesh density on dimensionless solutions, two values of $n$ are considered in this example, which are 10 and 500 .

From Figures 6 and 7, radial stress has a little error to the exact solution with the maximum error $2.13 \%$ and the minimum error $0.06 \%$. The circumferential stresses obtained in this study can finely match the exact solution with the maximum error $1.55 \%$ and minimum error $4.1 \times 10^{-4} \%$. Furthermore, the value of $n$ has great influence on the dimensionless solutions, and the dimensionless solutions for $n=500$ are obviously more accurate than that for $n=10$.
More different values of $n$ have been studied in this example, and we can find that the accuracy of dimensionless solutions will increase when the value of $n$ grows. However, when value of $n$ is larger than 500 , the value of $n$ has little influence on the dimensionless solutions. Therefore, to increase computational efficiency, the results of stresses and displacement for $n=500$ can be selected.

To analyze the reliability of solutions under the $\mathrm{M}-\mathrm{C}$ criterion, the stresses and displacement for the M-C surrounding rock obtained by the proposed dimensionless approach, and the approach by Lee and Pietruszczak [21] is compared. The parameters are presented as follows: $b=5.35 \mathrm{~m}, \sigma_{0}=3.31 \mathrm{MPa}, E=1.38 \mathrm{GPa}, \quad v=0.25, \quad c_{p}=$ $1 \mathrm{MPa}, c_{r}=0.7 \mathrm{MPa}, \phi_{p}=30^{\circ}, \quad \phi_{r}=22^{\circ}, \quad \alpha=3.5\left(\gamma^{p^{*}}=\right.$ $\left.(\alpha-1) \varepsilon_{\theta(1)}^{e}\right), \varphi_{p}=\varphi_{r}=3.75^{\circ}$, and $p_{i}=0 \mathrm{MPa}$. The computed stresses and displacement using two numerical approaches are illustrated in Figures 8 and 9.

The finite difference approach is also adopted by Lee and Pietruszczak [21]. The stress increment approach for the mechanical states of strain-softening rock mass is developed in their study. It can be seen from Figures 8 and 9, when $n=10$ and 100 , the determined circumferential stresses are respectively $10.2 \%$ and $4.5 \%$ larger than the circumferential stress in Lee and Pietruszczak [21]; meanwhile, the calculated displacements are respectively $11.1 \%$ and $3.2 \%$ smaller than the result in Lee and Pietruszczak [21]. When $n=500$ and 1000, the obtained stresses and displacements are almost the same as the counterparts in Lee and Pietruszczak [21]. Therefore, $n=500$ is selected in this study in order to reduce the calculation load, which can also meet the safety requirements in practical engineering. The comparisons in Figures 8 and 9 also verify the reliability of the proposed dimensionless approach for the M-C surrounding rock.

\subsection{Influence of the Deviatoric Plastic Shear Strain $\gamma^{p *}$ on the} Dimensionless Solutions of the Generalized $H$-B and $M-C$ Rock Mass. For the elastoplastic analysis in a strain-softening rock mass, the stresses and displacement are calculated in this study. The parameters which have great effects on the dimensionless solutions are chosen to be analyzed. Therefore, five values of the deviatoric plastic shear strain $\gamma^{p *}$ considered in this section are $0,0.004,0.008,0.012$, and 100 . Where $\gamma^{p^{*}}=$ 0 denotes the elastic-brittle-plastic behavior, and $\gamma^{p *}=100$ can be approximately regarded as elastic-perfectly plastic behavior. Furthermore, the data sets appearing in CarranzaTorres [26] was chosen as input parameters for the calculation in this section: $b=2 \mathrm{~m}, \sigma_{0}=15 \mathrm{MPa}, p_{i}=2.5 \mathrm{MPa}$, 


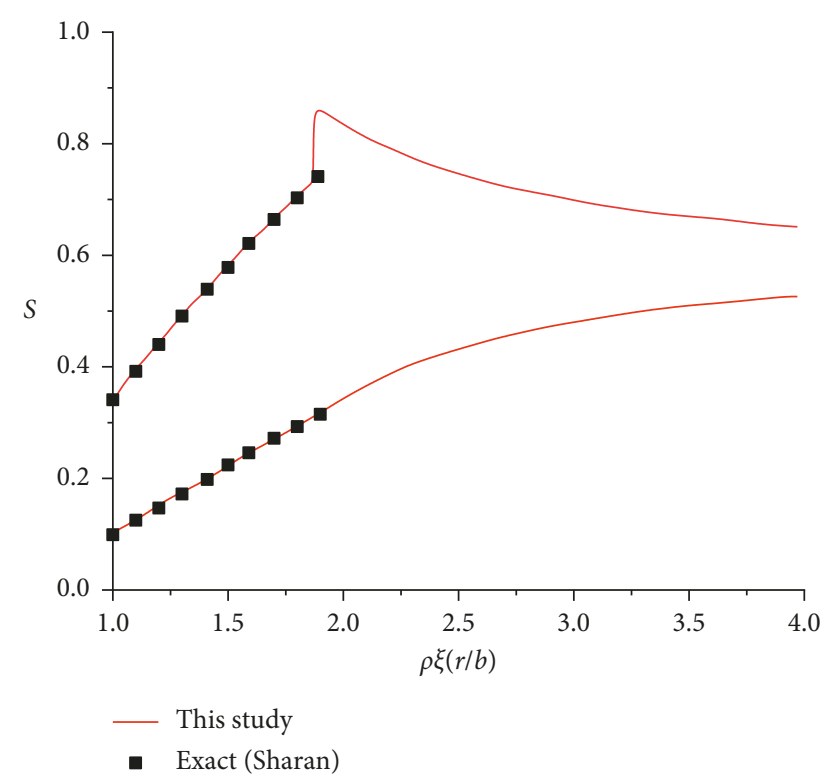

FIgURE 4: Comparison between dimensionless stresses and exact stresses for Hoek-Brown rock mass.

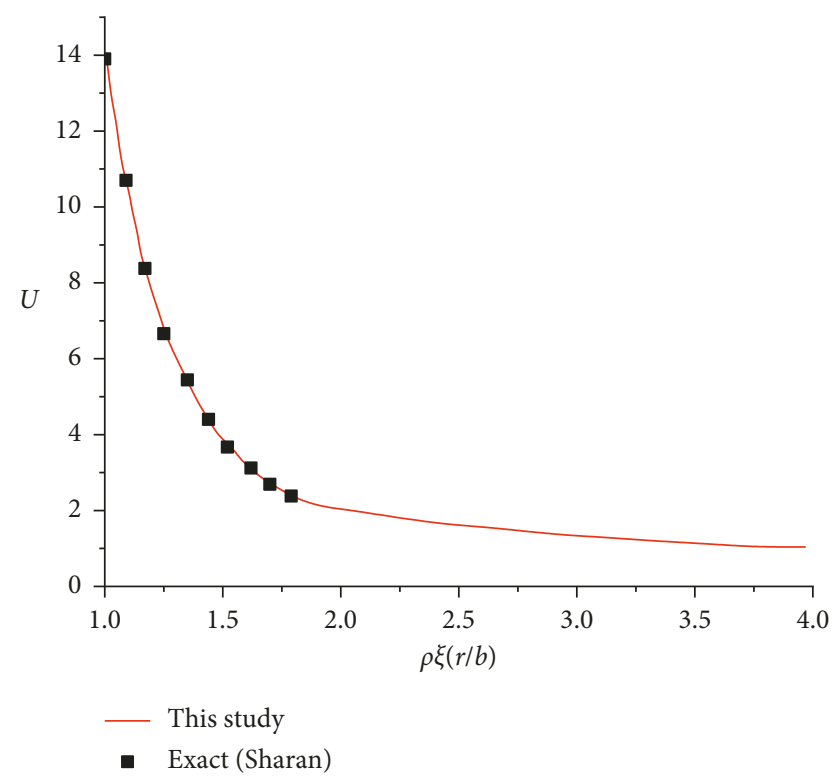

FIGURE 5: Comparison between dimensionless displacement and exact displacement for Hoek-Brown rock mass.

$E=5.7 \mathrm{GPa}, \quad v=0.3, \quad \sigma_{c p}=\sigma_{c r}=30 \mathrm{MPa}, \quad p_{i}=2.5 \mathrm{MPa}$, $m_{p}=1.7, s_{p}=0.0039, m_{r}=0.85, s_{r}=0.0019, a_{p}=0.55$, and $a_{r}=0.6$. The results are shown in Figures 10-13.

Figures 10 and 11 show the distributions of stresses and radial displacement with the change of $\gamma^{p *}$ based on the generalized Hoek-Brown rock mass, respectively. It should be noted that the solutions finely match the brittle-plastic solutions for the case of $\gamma^{p *}=0$. With the decrease of deviatoric plastic shear strain $\gamma^{p *}$, the strain-softening solutions converge to the brittle-plastic solutions. The plastic radius $R_{p}$ will grow with the decrease of deviatoric plastic shear strain $\gamma^{p *}$, which means the plastic zone becomes

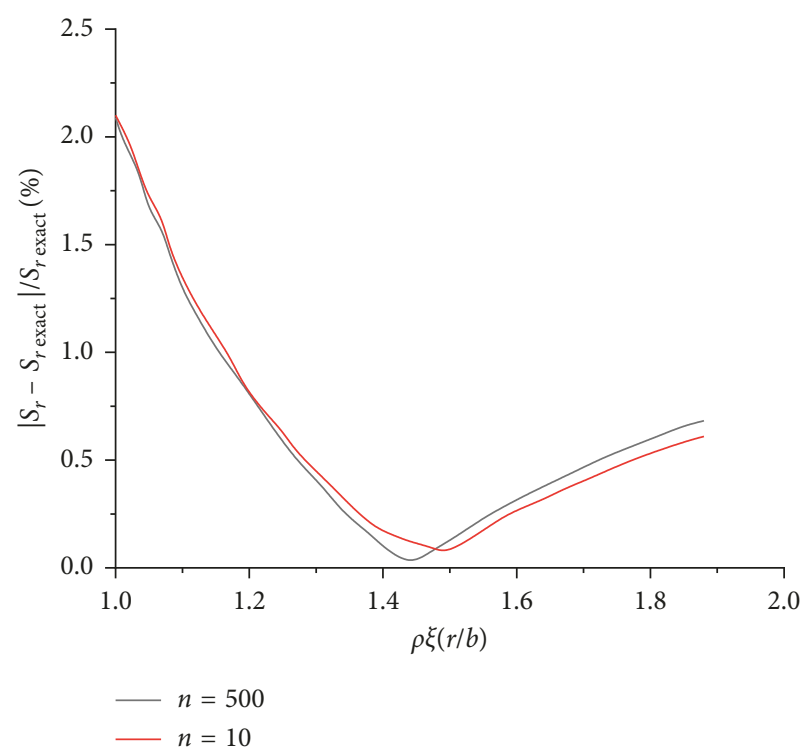

FIgURE 6: Distribution of errors between dimensionless stresses and exact stresses.

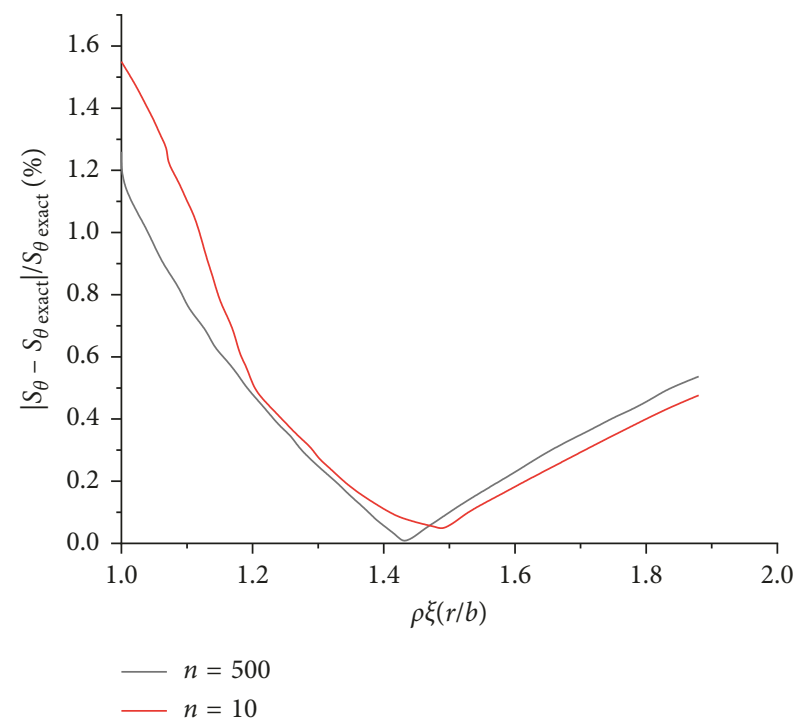

Figure 7: Distribution of errors between dimensionless displacement and exact displacement.

larger. For $\gamma^{p *}=0.0012$, the whole plastic zone is strainsoftening zone.

Figures 12 and 13 show the distributions of stresses and radial displacement with the change of $\gamma^{p *}$ based on the generalized $\mathrm{M}-\mathrm{C}$ rock mass, respectively. The results are similar to the generalized Hoek-Brown rock mass. With the decrease of deviatoric plastic shear strain $\gamma^{p *}$, the strainsoftening solutions converge to the brittle-plastic solutions. The plastic radius $R_{p}$ will reduce with the increase of deviatoric plastic shear strain $\gamma^{p *}$, which means the plastic zone becomes smaller. For $\gamma^{p *}=0.0012$, the whole plastic zone is strain-softening zone. Generally, the results reflect that the strain-softening behavior causes a smaller plastic 


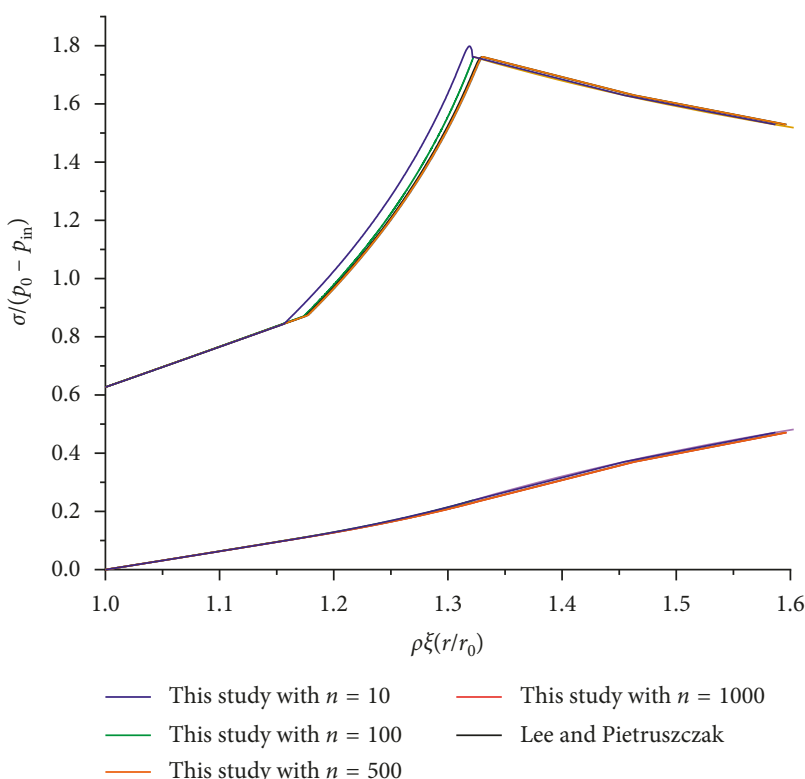

Figure 8: Comparison of dimensionless stresses for M-C rock mass.

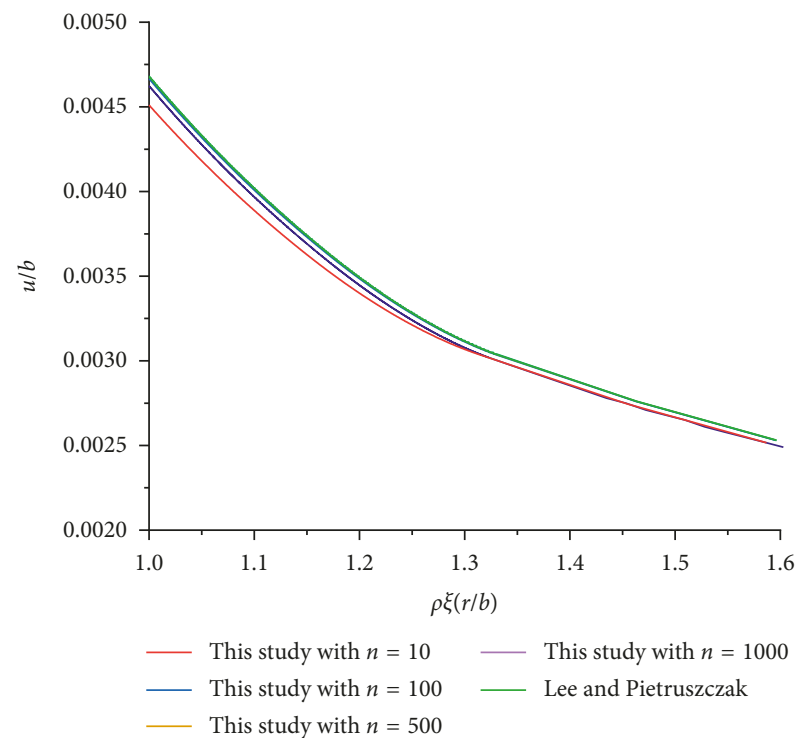

Figure 9: Comparison of dimensionless displacement for M-C rock mass.

radius and the strain-softening behavior will become obvious with the decrease of plastic radius.

\subsection{Influence of the Strength Parameters on the Dimensionless} Solutions for the Generalized H-B Rock Mass. Alonso et al. [1] presented self-similar solutions in a strain-softening rock mass based on the generalized Hoek-Brown failure criterion for $a=0.5$ However, the general strain-softening solutions are still not available now. Many scholars have made deep studies of the strength parameter $a$ and find that it varies in accordance with the geological conditions. The strength parameter $a$ can be formulated by

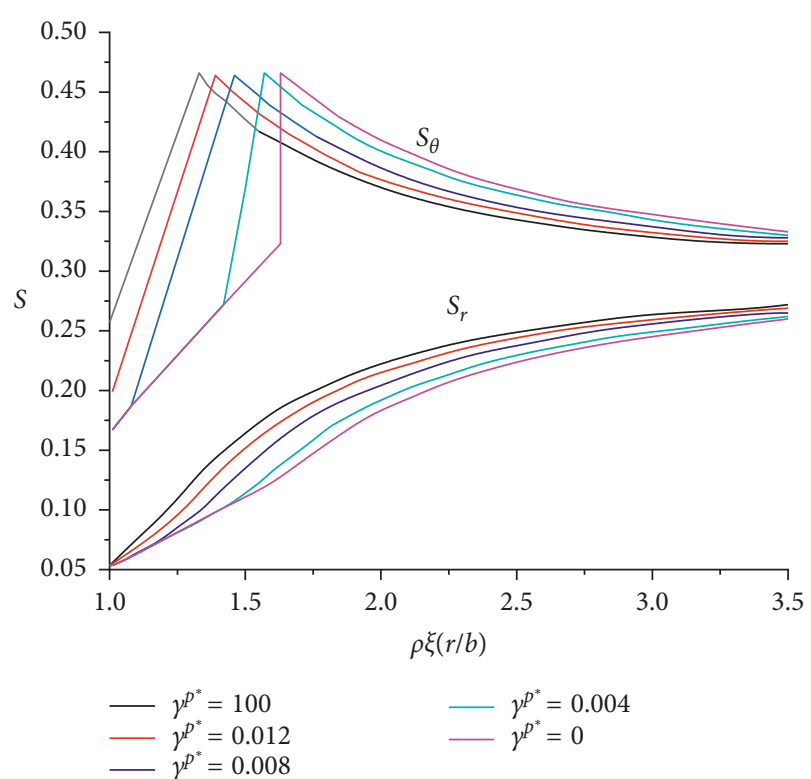

Figure 10: Variation of the dimensionless radial and circumferential stresses with the change of $\gamma^{p *}$ based on the generalized Hoek-Brown rock mass.

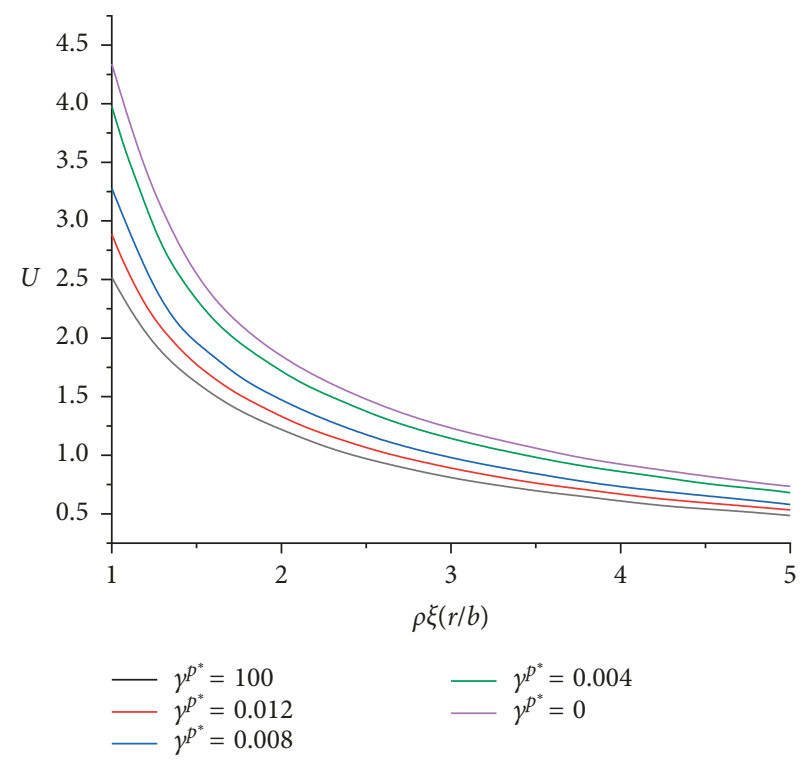

FIGURE 11: Variation of the dimensionless radial displacement with the change of $\gamma^{p *}$ based on the generalized Hoek-Brown rock mass.

$$
a=\frac{1}{2}+\frac{1}{6}\left(e^{-\mathrm{GSI} / 15}-e^{-20 / 3}\right),
$$

where GSI is the geological strength index which indicates the degree of fracturing and the condition of fracture surfaces of rock mass. Since the value of GSI is in the range from 10 to $100, a$ can take a value in the range of 0.5-0.6. Therefore, it is necessary to find how the strength parameter $a$ affects the dimensionless solutions of the generalized H-B rock mass. In this study, different values of $a$ are analyzed, and the results are shown from Figures 14-19. 


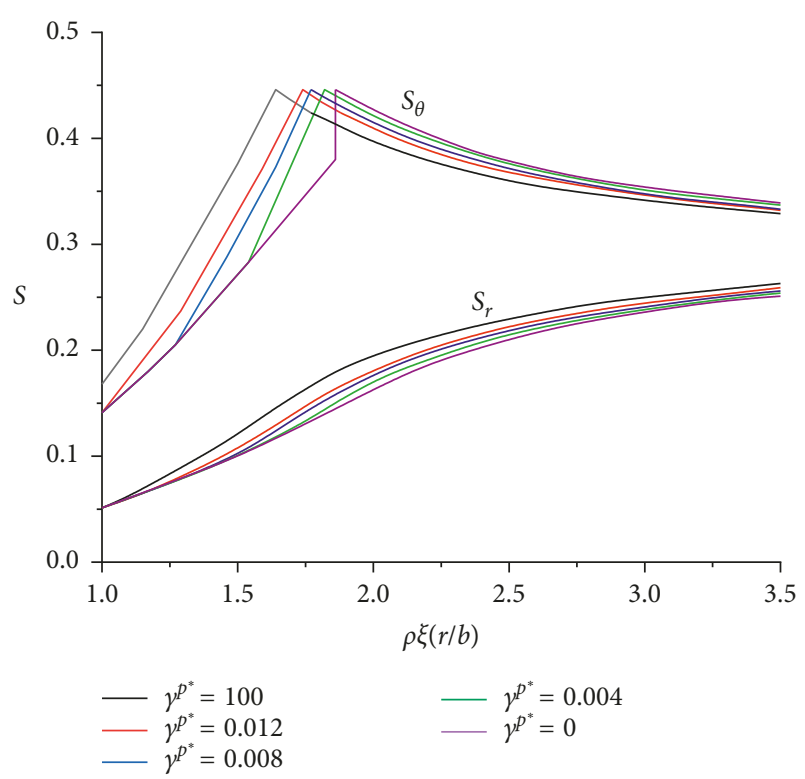

FIGURE 12: Variation of the dimensionless radial and circumferential stresses with the change of $\gamma^{p *}$ based on the M-C rock mass.

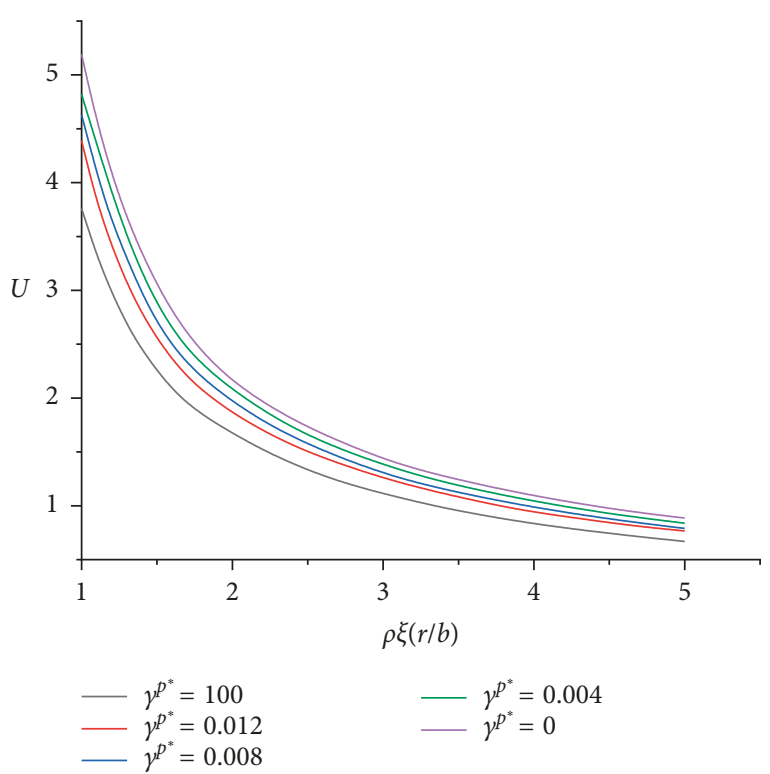

FIGURE 13: Variation of the dimensionless radial displacement with the change of $\gamma^{p *}$ based on the M-C rock mass.

Figure 14 shows the distribution of the dimensionless stresses with different values of $a$. When the softening zone is much thinner than the residual zone, the plastic behavior will be shifted quickly to residual regime.

It can be noted that the strength parameters $a_{p}$ and $a_{r}$ have an obvious influence on the dimensionless solutions. The plastic radius $R_{p}$ will grow when $a_{p}$ and $a_{r}$ become larger, which means the plastic zone becomes larger. When $a_{p}$ remains unchanged and $a_{r}$ becomes larger, the plastic radius will increase. In addition, the residual zone will increase with the increase of $a_{p}$ and $a_{r}$.

Figure 15 shows the influence of different values of $a_{p}$ and $a_{r}$ on the radial displacement based on the generalized

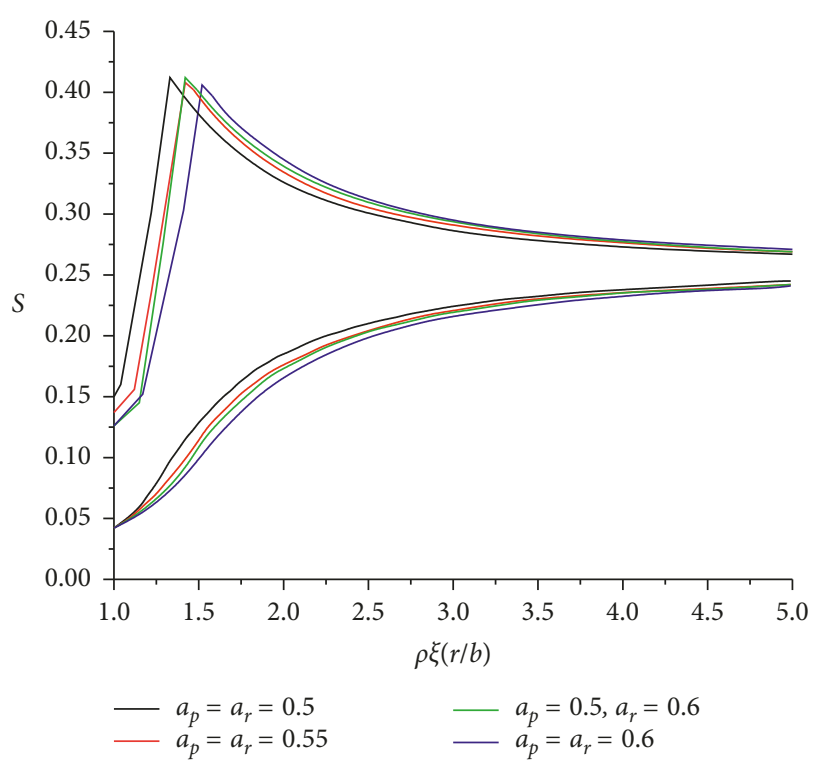

FIGURE 14: Distribution of radial and circumferential stresses for different values of $a$.

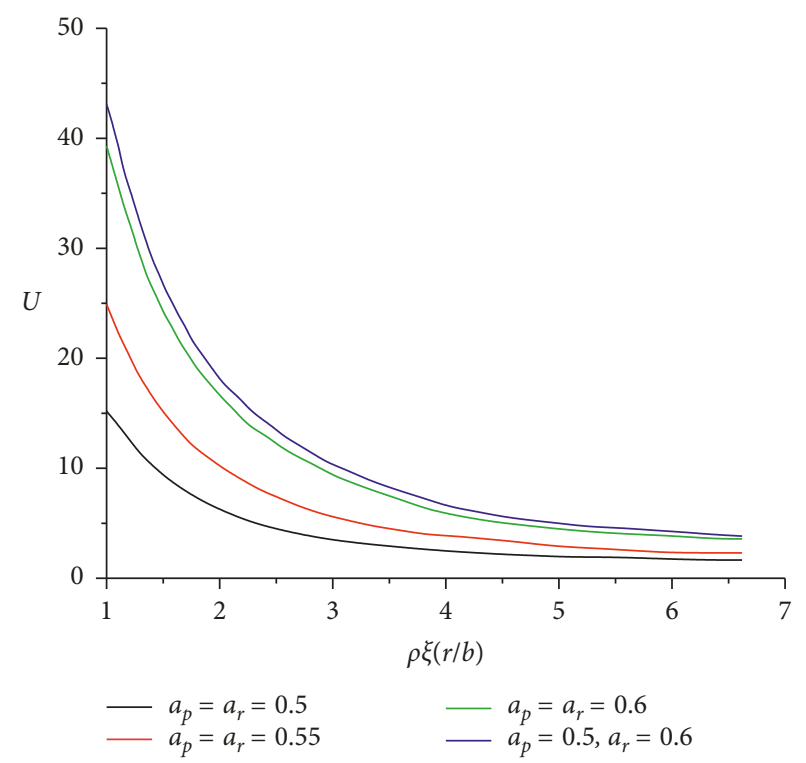

FIGURE 15: Distribution of radial displacement for different values of $a$.

Hoek-brown failure criterion. Besides Figure 16 shows the variation of radial displacement on the opening surface with different values of $a$.

As can be seen in Figure 15, the strength parameters $a_{p}$ and $a_{r}$ have an obvious influence on the dimensionless displacement. The radial displacement grows rapidly with the increase of $a_{p}$ and $a_{r}$. From Figure 16, the dimensionless displacement for $a_{p}=a_{r}=0.6$ is about 1.4 times larger than that for $a_{p}=a_{r}=0.5$. When translating the dimensionless displacement into actual displacement, we can find that the displacement for $a_{p}=a_{r}=0.6$ is about 3 times larger than that for $a_{p}=a_{r}=0.5$.

Figure 17 shows the variation of plastic radius $R_{p}$ on the opening surface with the change of the parameter $a$, based 


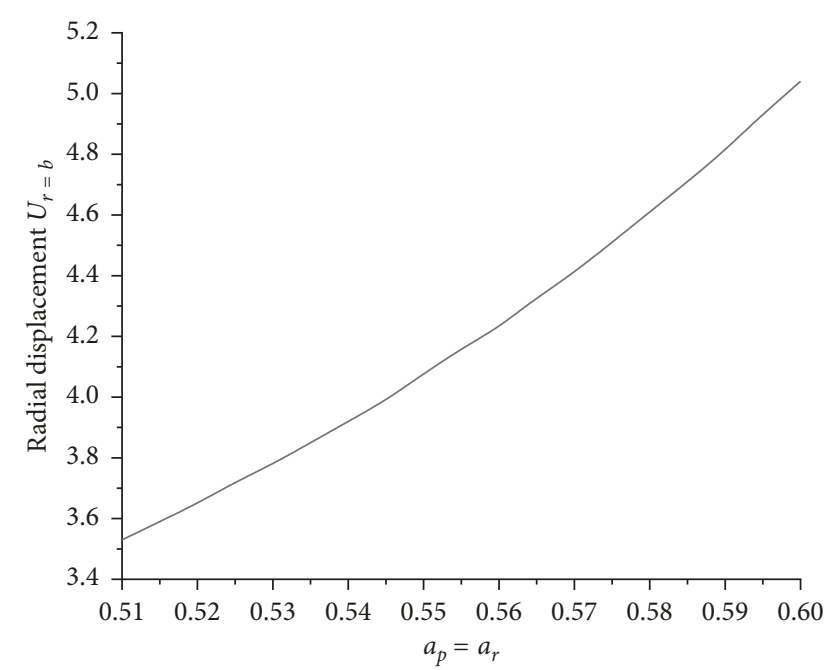

FIGURE 16: Variation of radial displacement on the opening surface with different values of $a$.

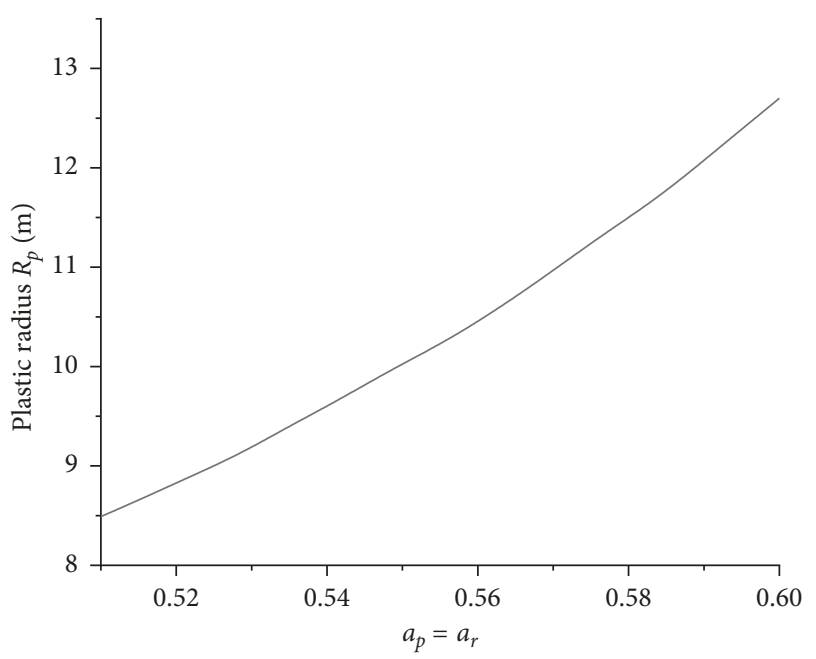

FIGURE 17: Variation of plastic radius $R_{p}$ on the opening surface with the change of $a$.

on the generalized Hoek-brown failure criterion. The strength parameters $a_{p}$ and $a_{r}$ have an obvious influence on the plastic radius $R_{p}$. The radial displacement grows rapidly with the increase of $a_{p}$ and $a_{r}$. The plastic $R_{p}$ for $a_{p}=a_{r}=$ 0.6 is about 1.5 times larger than that for $a_{p}=a_{r}=0.5$.

Figures 18 and 19 show the variation of dimensionless radial displacement on the opening surface with the change of $\sigma_{0}$ and $P_{0}$ based on the generalized Hoek-brown failure criterion, respectively. From Figure 18, the radial displacement for brittle-plastic behavior rapidly grows, and the radial displacement for elastic-perfectly plastic behavior raises slowly with the increase of $\sigma_{0}$. As can be seen from Figure 19, the radial displacement for brittle-plastic behavior gradually grows with the increase of $P_{0}$ and the radial displacement for elastic-perfectly plastic behavior increases slowly, which reflects that $\sigma_{0}$ has little influence on dimensionless radial displacement when the deviatoric plastic shear strain $\gamma^{p *}$ becomes larger.

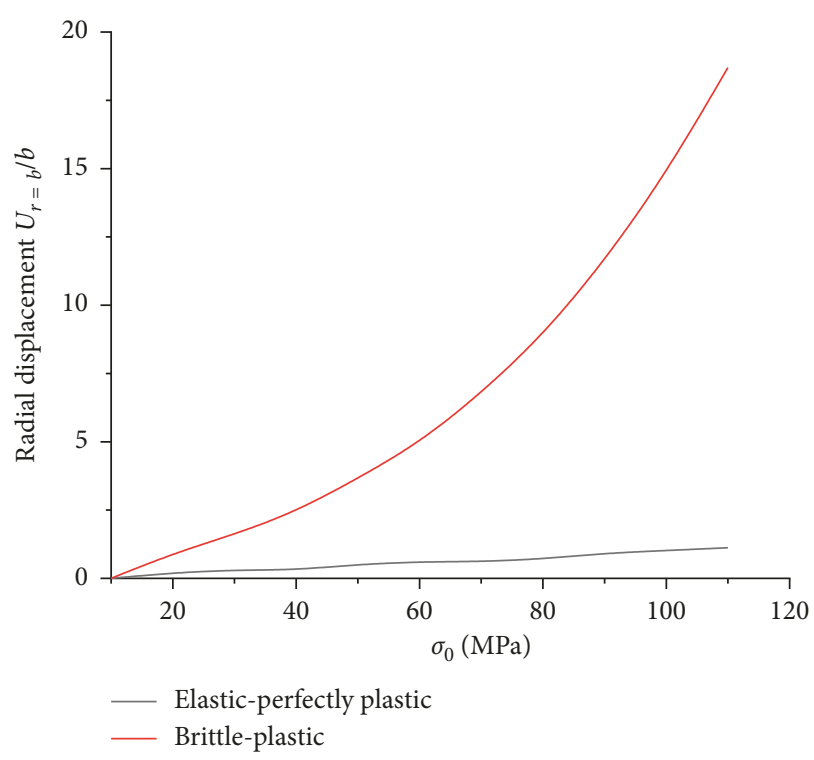

FIGURE 18: Variation of radial displacement on the opening surface with the change of $\sigma_{0}$ based on generalized Hoek-Brown failure criterion.

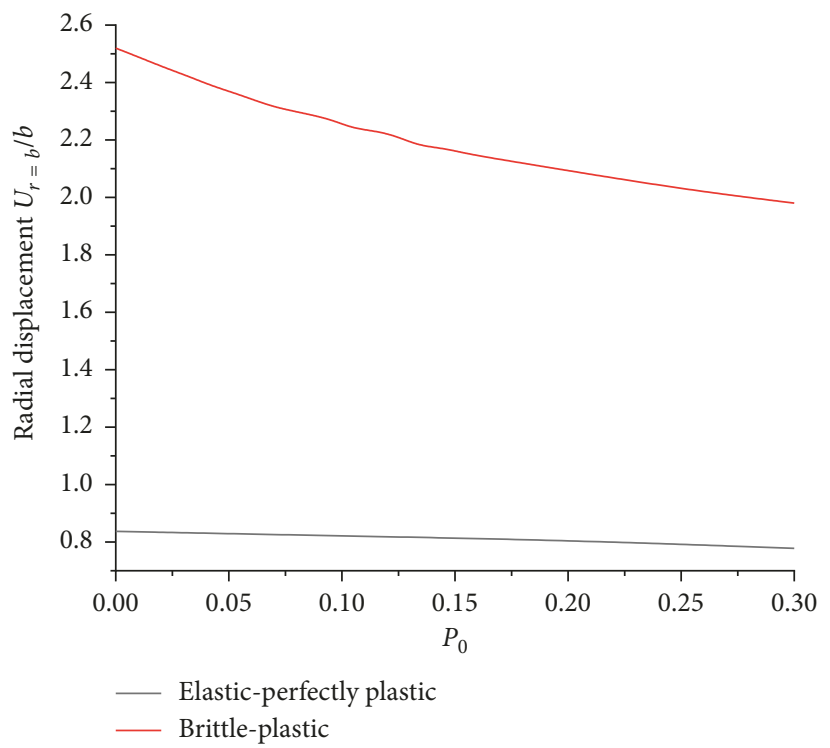

FIGURE 19: Variation of radial displacement on the opening surface with the change of $P_{0}$ based on generalized Hoek-Brown failure criterion.

Overall, we can draw some conclusions: different values of $a$ have an obvious influence on the dimensionless solutions. The plastic radius $R_{p}$ and the radial displacement increase with the increase of $a$. The radial displacement for brittle-plastic behavior rapidly grows with $\sigma_{0}$ increasing and the radial displacement for elastic-perfectly plastic behavior raises slowly, which reflects that $\sigma_{0}$ has great influence on dimensionless radial displacement when the deviatoric plastic shear strain $\gamma^{p *}$ becomes smaller. As can be seen from Figure 19, the radial displacement for brittle-plastic behavior gradually grows with the increase of $P_{0}$ and the radial displacement for elastic-perfectly plastic behavior increases 
slowly, which reflects that $P_{0}$ has little influence on dimensionless radial displacement when the deviatoric plastic shear strain $\gamma^{p *}$ becomes larger.

\section{Analysis of a Circular Opening Excavated in a Strain-Softening Rock Mass considering Seepage Force}

In practical engineering, the seepage force has significant influence on the rock mass surrounding tunnel, especially when considering the strain-softening behavior. Most diseases are related to the seepage force directly or indirectly. However, the elastoplastic analysis of a circular opening excavated in a strain-softening rock mass considering seepage force may be obtained by the dimensionless method, and the exact solutions are difficult to accomplish. Therefore, based on the generalized Hoek-Brown failure criterion, the dimensionless method is used for reconstruction of the stepstress approach to analyze the strain-softening rock mass considering seepage force. Then, a new dimensionless method for the elastoplastic analysis of a circular opening excavated in a strain-softening rock mass considering seepage force is established in this study.

5.1. Seepage Force. For the circular tunnel with inner radius $\left(r_{0}\right)$, water head $\left(h_{a}\right)$ acts on the tunnel wall and water head of hydrostatic pressure $\left(h_{0}\right)$ is far from the tunnel wall. It is assumed that hydraulic conductivity of the surrounding rock is the same in all directions. The main seepage flow is along radial direction, and the continuity seepage differential equation can be written as follows:

$$
\frac{\partial^{2} H}{\partial r^{2}}+\frac{1}{r} \frac{\partial H}{\partial r}=0
$$

In Equation (62), $H(r)_{r=r_{0}}=h_{a}$ and $H(r)_{r=\infty}=h_{0}$ are the boundary conditions. Equation (61) can be solved by replacing the second condition $\left(H(r)_{r=\infty}=h_{0}\right)$ with $H(r)_{r=\alpha r_{0}}=h_{0}$. Therefore, the solution of Equation (63) is given by

$$
H=\frac{1}{\ln \alpha}\left(h_{a} \ln \frac{\alpha r_{0}}{r}+h_{0} \ln \frac{r}{r_{0}}\right),
$$

where $a$ is a constant of seepage force, and a conveniently large value can be taken if it meets the engineering accuracy need. In terms of Li et al. [24], $\alpha=30$ is selected in this study.

For the axisymmetric plane strain problem, seepage force is the volume force and is given by

$$
F_{r}=-\gamma_{w} i=-\gamma_{w} \frac{d(\varsigma H)}{d r}=\frac{\gamma_{w} \varsigma\left(h_{a}-h_{0}\right)}{r \ln \alpha},
$$

where $i$ means hydraulic gradient, $\varsigma$ is the rock effective coefficient of pore water pressure, $H$ denotes the water level fluctuation, $\alpha$ is the constant of seepage force, $\gamma_{w}$ is the unit weight of water, $r$ is the radial distance from center of the opening, and $h_{0}$ and $h_{a}$ are the initial and final water levels, respectively.
5.2. Solutions for Stresses and Displacement considering Seepage Force. Considering the influence of seepage force, stress equilibrium differential equation can be expressed as follows:

$$
\frac{d \sigma_{r}}{d r}+\frac{\sigma_{r}-\sigma_{\theta}}{r}+F_{r}=0
$$

As is mentioned before, it is assumed that the yielding of the rock mass is governed by the yielding function:

$$
f\left(\sigma_{\theta}, \sigma_{r}\right)=\sigma_{\theta}-\sigma_{r}-H\left(\sigma_{r}, \gamma^{p}\right)=0 .
$$

In order to work with dimensionless field quantities, the stress magnitude, $\sigma_{0}-\sigma_{r}^{*}$, is used to normalize the stresses:

$$
\begin{aligned}
& \tilde{\sigma}_{\theta}=\frac{\sigma_{\theta}}{\sigma_{o}-\sigma_{r}^{*}}, \\
& \tilde{\sigma}_{r}=\frac{\sigma_{r}}{\sigma_{o}-\sigma_{r}^{*}} .
\end{aligned}
$$

Strains are normalized accordingly, considering the extra term 2G:

$$
\begin{aligned}
& \widetilde{\varepsilon}_{\theta}=\frac{2 G}{\sigma_{o}-\sigma_{r}^{*}} \varepsilon_{\theta}, \\
& \widetilde{\mathcal{\varepsilon}}_{r}=\frac{2 G}{\sigma_{o}-\sigma_{r}^{*}} \varepsilon_{r} .
\end{aligned}
$$

Displacement is normalized in terms of the radius $b$ :

$$
\tilde{u}_{r}=\frac{2 G}{b\left(\sigma_{o}-\sigma_{r}^{*}\right)} u_{r} \text {. }
$$

Similarly, the step-stress approach is used to divide the plastic zone into a finite number of concentric rings which satisfy the equilibrium and compatibility equations in strainsoftening rock mass. The increments of stresses and strains for each annulus are obtained by solving the equilibrium and compatibility equations. Then, the stresses and displacements in the softening zone can be calculated.

When considering the effects of seepage force, a stepstress approach is used for solving the stresses and displacement in the plastic zone numerically. The whole plastic zone is divided into $\mathrm{n}$ annuli with a constant radial stress increment between the adjacent two annuli, which is defined as follows:

$$
\Delta \widetilde{\sigma}_{r}=\frac{p_{i}-\sigma_{0}}{n}
$$

So that the stress components for the $i$ th annulus may be presented by the following equation:

$$
\tilde{\sigma}_{r(i)}=\tilde{\sigma}_{r(i-1)}+\Delta \tilde{\sigma}_{r} .
$$

Then, the circumferential stress can be written as follows:

$$
\tilde{\sigma}_{\theta(i)}=\tilde{\sigma}_{r(i)}+H\left(\tilde{\sigma}_{r(i)}, \gamma_{(i-1)}^{p}\right) \text {. }
$$

According to Hooke's law, the elastic strain increments are related to the stress increment. That is, 


$$
\left\{\begin{array}{c}
\Delta \widetilde{\mathcal{\varepsilon}}_{r(i)} \\
\Delta \widetilde{\varepsilon}_{\theta(i)}
\end{array}\right\}=\frac{2 G(1+v)}{E}\left[\begin{array}{cc}
1-v & -v \\
-v & 1-v
\end{array}\right]\left\{\begin{array}{c}
\Delta \widetilde{\sigma}_{r(i)} \\
\Delta \widetilde{\sigma}_{\theta(i)}
\end{array}\right\} .
$$

When the number of annuli $n$ is sufficiently large, substituting Equation (64) into Equation (65), the equilibrium equation can be transformed as follows:

$$
\frac{d \widetilde{\sigma}_{r}}{d \rho}+\frac{\widetilde{\sigma}_{r}-\widetilde{\sigma}_{\theta}}{\rho}+\frac{\gamma_{w} \varsigma\left(h_{a}-h_{0}\right)}{\rho \ln \alpha}=0,
$$

or

$$
\frac{d \widetilde{\sigma}_{r}}{d \rho}+\frac{H\left(\widetilde{\sigma}_{r}, \gamma^{p}\right)}{\rho}+\frac{\gamma_{w} \varsigma\left(h_{a}-h_{0}\right)}{\rho \ln \alpha}=0 .
$$

Equation (75) can be approximated for the $i$ th annulus as

$$
\frac{\widetilde{\sigma}_{r(i)}-\widetilde{\sigma}_{r(i-1)}}{\rho_{(i)}-\rho_{(i-1)}}+\frac{H\left(\overline{\tilde{\sigma}}_{r(i)}, \gamma_{(i-1)}^{p}\right)}{\rho_{(i)}+\rho_{(i-1)}}+\frac{\gamma_{w} \varsigma\left(h_{a}-h_{0}\right)}{\left(\rho_{(i)}+\rho_{(i-1)}\right) \ln \alpha}=0,
$$

where $\overline{\widetilde{\sigma}}_{r(i)}=\left(\widetilde{\sigma}_{r(i)}+\widetilde{\sigma}_{r(i-1)}\right) / 2$.

Then, the inner radius can be obtained by

$$
\rho_{(i)}=\frac{2 H\left(\overline{\tilde{\sigma}}_{r(i)}, \gamma_{(i-1)}^{p}\right)+\gamma_{w} \varsigma\left(h_{a}-h_{0}\right) / \ln \alpha+\Delta \widetilde{\sigma}_{r}}{2 H\left(\overline{\widetilde{\sigma}}_{r(i)}, \gamma_{(i-1)}^{p}\right)+\gamma_{w} \varsigma\left(h_{a}-h_{0}\right) / \ln \alpha-\Delta \widetilde{\sigma}_{r}} \rho_{(i-1)} .
$$

The strain components are given in Equation (36), and rearranging for $\widetilde{\varepsilon}_{\theta}^{p}$ gives, in view of Equations (8), (73), and (77), the following equation:

$$
\begin{aligned}
\left(\frac{1}{\Delta \rho_{(i)}}+\left(1+k_{(i-1)}\right) \frac{1}{\bar{\rho}_{(i)}}\right) \Delta \widetilde{\varepsilon}_{\theta(i)}^{p} & \\
= & -\frac{\Delta \widetilde{\varepsilon}_{\theta(i)}^{e}}{\Delta \rho_{(i)}}-\frac{2 G(1+v)}{E} \\
& \cdot \frac{H\left(\overline{\widetilde{S}}_{r(i)}, \gamma_{(i-1)}^{p}\right)+\left(\gamma_{w} \varsigma\left(h_{a}-h_{0}\right) / \ln \alpha\right)}{\bar{\rho}_{(i)}} \\
& -\frac{1}{\bar{\rho}_{(i)}}\left(\widetilde{\varepsilon}_{\theta(i-1)}^{p}-\widetilde{\varepsilon}_{r(i-1)}^{p}\right),
\end{aligned}
$$

where $\bar{\rho}_{(i)}=\left(\bar{\rho}_{(i-1)}+\bar{\rho}_{(i)}\right) / 2$ and $k_{(i-1)}=\left(1+\sin \varphi_{(i-1)}\right) /$ $\left(1-\sin \varphi_{(i-1)}\right)$. The deviatoric plastic shear strain is updated as

$$
\gamma_{(i)}^{p}=\gamma_{(i-1)}^{p}+\left(\Delta \widetilde{\varepsilon}_{\theta(i)}^{p}-\Delta \widetilde{\varepsilon}_{r(i)}^{p}\right) .
$$

The total strain at the $i$ th annulus can be given as follows:

$$
\left\{\begin{array}{c}
\widetilde{\varepsilon}_{r(i)} \\
\widetilde{\varepsilon}_{\theta(i)}
\end{array}\right\}=\left\{\begin{array}{c}
\widetilde{\varepsilon}_{r(i-1)} \\
\widetilde{\varepsilon}_{\theta(i-1)}
\end{array}\right\}+\left\{\begin{array}{c}
\Delta \widetilde{\varepsilon}_{r(i)}^{e} \\
\Delta \widetilde{\mathcal{\varepsilon}}_{\theta(i)}^{e}
\end{array}\right\}+\left\{\begin{array}{c}
\Delta \widetilde{\varepsilon}_{r(i)}^{p} \\
\Delta \widetilde{\varepsilon}_{\theta(i)}^{p}
\end{array}\right\} .
$$

According to Equations (68) and (69), the relationship, $\varepsilon_{\theta}=u / R$, can be recalled as

$$
\widetilde{\varepsilon}_{\theta}=\frac{\tilde{u}}{\rho \xi R_{p}} .
$$

Then, the displacement normalized by plastic radius $R_{p}$ can be obtained as follows:

$$
\widetilde{U}_{(i)}=\widetilde{\varepsilon}_{\theta(i)} r_{(i)}=\widetilde{\varepsilon}_{\theta(i)} \rho_{(i)} \xi,
$$

where $\widetilde{U}_{(i)}=\widetilde{u}_{(i)} / R_{p}$.

Plastic radius $R_{p}$ can be calculated from the following relationship:

$$
R_{p}=\frac{b}{r_{(n)}}=\frac{1}{\rho_{(n)} \xi}
$$

5.3. Verification Examples. The dimensionless stresses and displacements in this study can be obtained by programming the dimensionless method into MATLAB codes. In order to examine the difference between the solutions with and without considering seepage force, the parameters are adopted as follows: $b=5 \mathrm{~m}, \sigma_{0}=30 \mathrm{MPa}, p_{i}=5 \mathrm{MPa}$, $E=5 \mathrm{GPa}, \quad v=0.25, \quad \sigma_{c p}=\sigma_{c r}=30 \mathrm{MPa}, m_{p}=1.7, \quad s_{p}=$ $0.0039, \quad m_{r}=1.0, \quad \gamma^{p}=0, \quad s_{r}=0.0, \quad a_{p}=a_{r}=0.5, \quad \gamma_{w}=$ $9.8 \mathrm{kN} / \mathrm{m}^{3}, \varsigma=1, h_{a}=50 \mathrm{~m}, h_{0}=0$, and $\alpha=30$. The results are shown in Figures 20 and 21.

Figures 20 and 21 show the comparison between dimensionless solutions considering seepage force and solutions without considering seepage force. As can be seen from Figure 20, the seepage force has a great influence on the dimensionless stresses. The variation law of stresses considering seepage force is coincident with that without considering seepage force. But the plastic radius considering seepage force is larger than that without considering seepage force, which results from the increase of effective stress of the surrounding rock when the effects of seepage force are considered. The results reflect that seepage force can increase the effective stresses of the surrounding rock. From Figure 21, the dimensionless displacement is also be affected by the seepage force. The variation law of displacement considering seepage force is coincident with that without considering seepage force, and the plastic displacement considering seepage force is larger than that without considering seepage force.

Figures 22 and 23 show the distributions of stresses and radial displacement considering seepage force with different $\gamma^{p *}$ for the generalized H-B rock mass, respectively. It should be noted that the variation law of stresses considering seepage force agrees with that without considering seepage force. The plastic radius $R_{p}$ will reduce when the deviatoric plastic shear strain $\gamma^{p *}$ increases. When the deviatoric plastic shear strain is close to 0 , the solutions finely match the brittle-plastic solutions. The largest plastic zone appears in brittle-plastic case, and the thinnest plastic zone develops for the case of elastic-perfectly plastic rock mass.

5.4. Analysis of Influencing Factors of the Dimensionless Solutions considering Seepage Force. Based on the generalized Hoek-Brown failure criterion, the parameter $a$ is selected as 


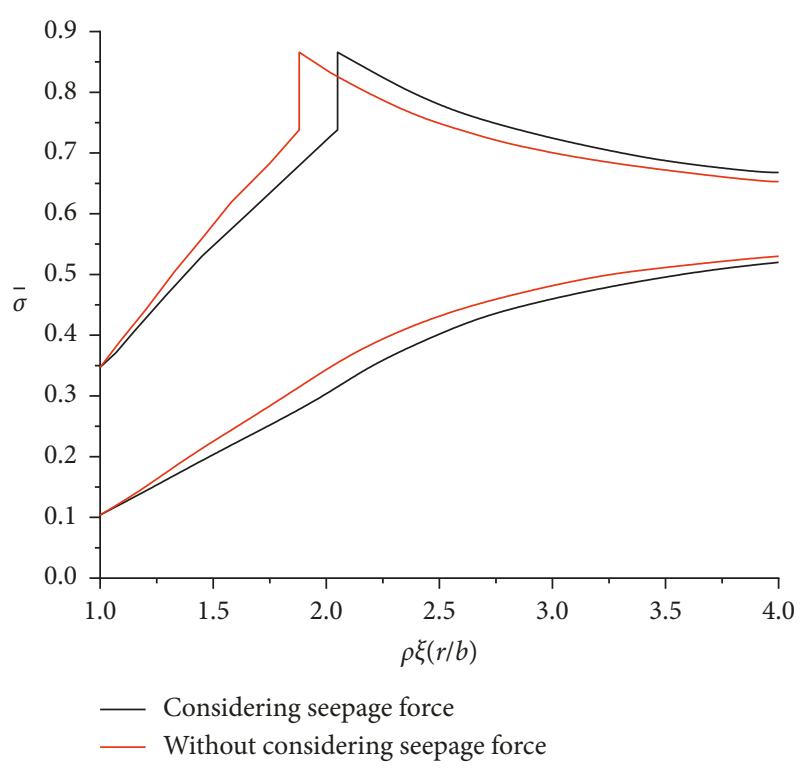

FIgURE 20: Comparison between dimensionless stresses with and without considering seepage force for Hoek-Brown rock mass.

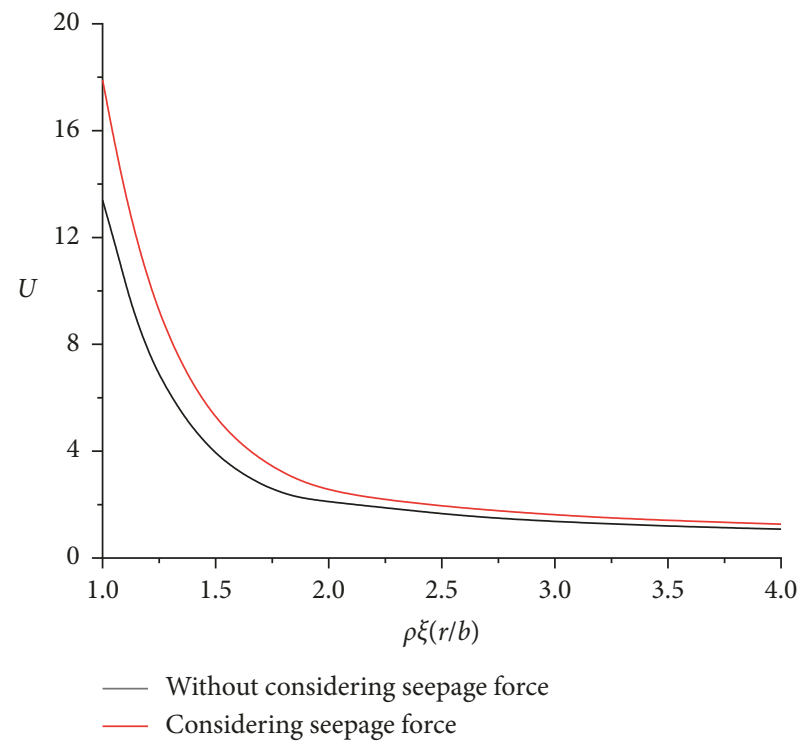

FIgURE 21: Comparison between dimensionless displacement with and without considering seepage force for Hoek-Brown rock mass.

an influencing factor of the dimensionless solutions considering seepage force. The influence of different values of $a$ on the dimensionless stresses and displacement is shown from Figures 24-27.

Figure 24 shows four ground reactions curves based on different values of $a$. Three curves among them postulate that the peak and residual values of $a$ are equal to $0.5,0.55$, and 0.6 , respectively. The differences in the shape of those curves seem substantial, especially when $p_{i}$ is very low. The curves for $a_{p}=$ 0.5 and $a_{p}=0.6$ is close to that for $a_{p}=a_{r}=0.6$, this is because the thickness of the strain-softening zone in this problem is very narrow as is inferred in Figure 24, in which the radial and circumferential stresses for $p_{i}=0$ are displayed.

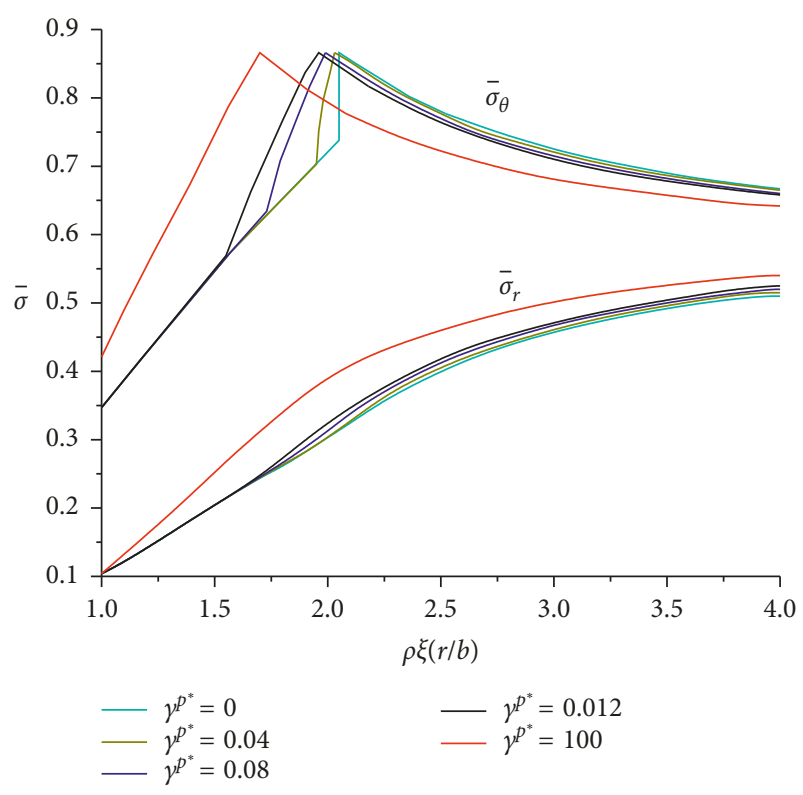

FIGURE 22: Variation of the dimensionless radial and circumferential stresses considering seepage force with the change of $\gamma^{p *}$ for the generalized Hoek-Brown rock mass.

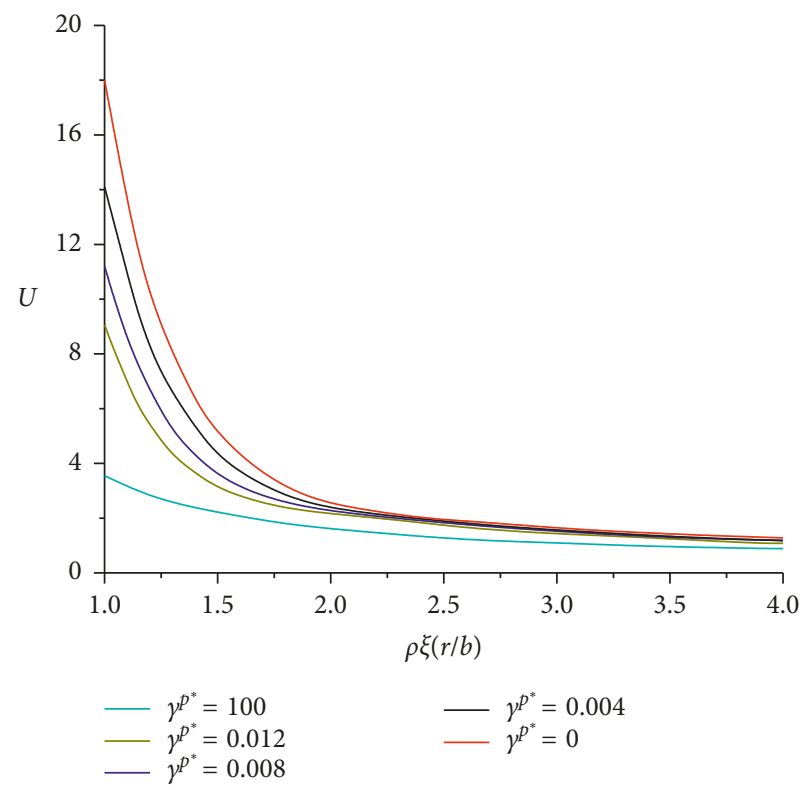

FIGURE 23: Variation of the dimensionless radial displacement considering seepage force with the change of $\gamma^{p *}$ for the generalized Hoek-Brown rock mass.

Figure 25 shows the distribution of the dimensionless stresses for different values of $a$. When the strain-softening zone is much thinner than the residual zone, the plastic behavior will be shifted quickly to residual regime.

As can be seen from Figure 25, when seepage force is considered, the variation law is coincident with that without considering seepage force. It can also be noted that the strength parameters $a_{p}$ and $a_{r}$ have an obvious influence on the dimensionless solutions when considering seepage force. When $a_{p}=a_{r}$, the plastic radius $R_{p}$ will grow when the $a_{p}$ 


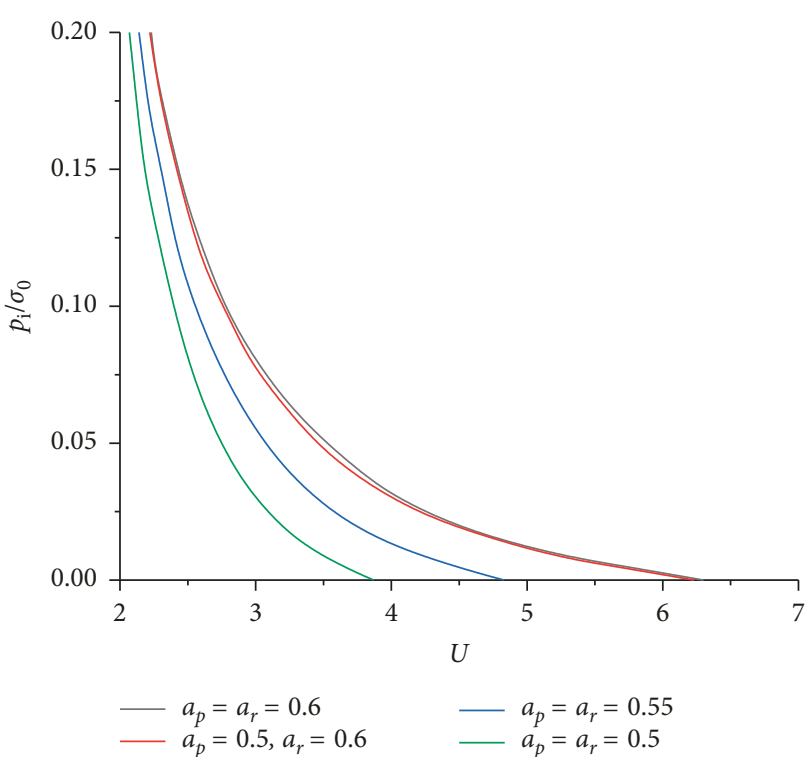

FIGURE 24: Ground reaction curves for different $a$ for the generalized $\mathrm{H}-\mathrm{B}$ rock mass.

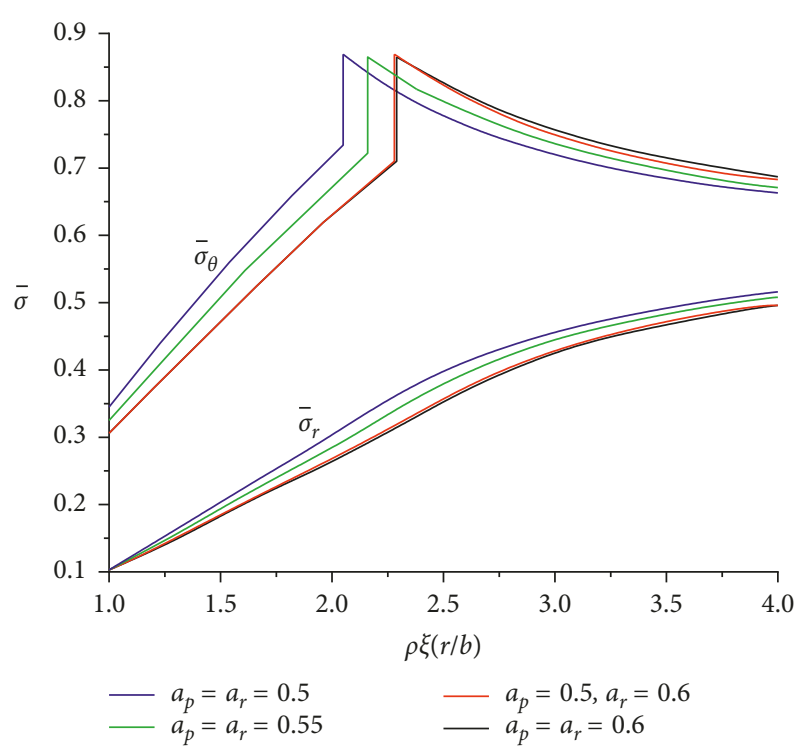

FIGURE 25: Distribution of radial and circumferential stresses for different values of $a$ for the generalized H-B rock mass.

and $a_{r}$ become larger. In addition, the stresses for $a_{p}=a_{r}=$ 0.5 are very close to that for $a_{p}=0.5$ and $a_{p}=0.6$, which denotes that the difference of $a_{p}$ and $a_{r}$ has little effects on the stresses when considering seepage force.

Figures 26 and 27 show the influence of different values of $a_{p}$ and $a_{r}$ on the radial radius based on the generalized Hoek-brown failure criterion and the variation of radial displacements on the opening surface with different values of parameter $a$.

As are illustrated in Figure 26, the strength parameters $a_{p}$ and $a_{r}$ have an obvious influence on the plastic radius $R_{p}$. The plastic radius grows with the increase of $a_{p}$ and $a_{r}$. However, the plastic radius decreases rapidly with the increase of the support pressure $p_{i}$. Furthermore, the influence

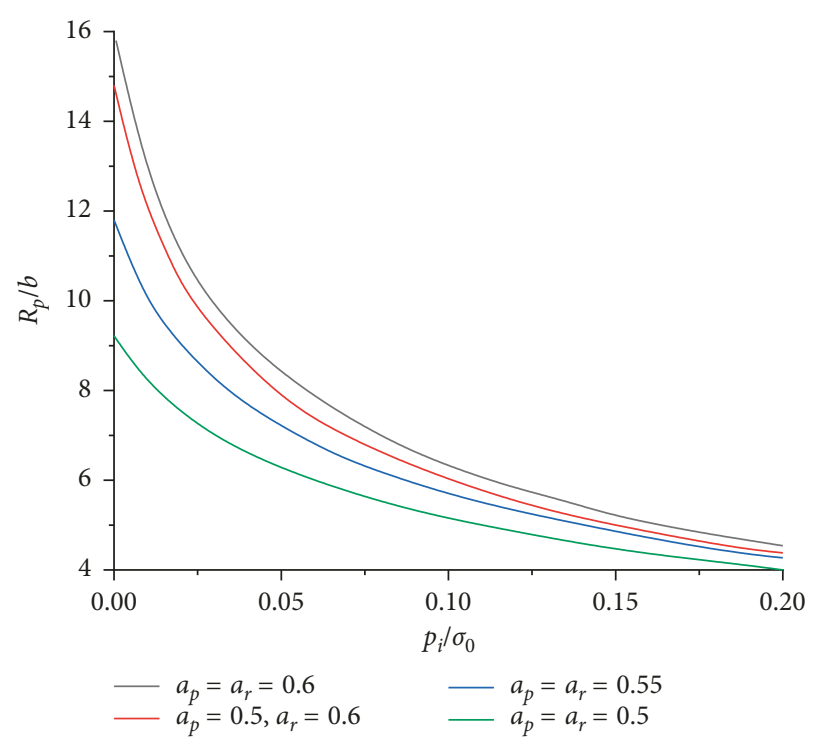

FIGURE 26: Evolution of plastic radii for different values of $a$ considering seepage force.

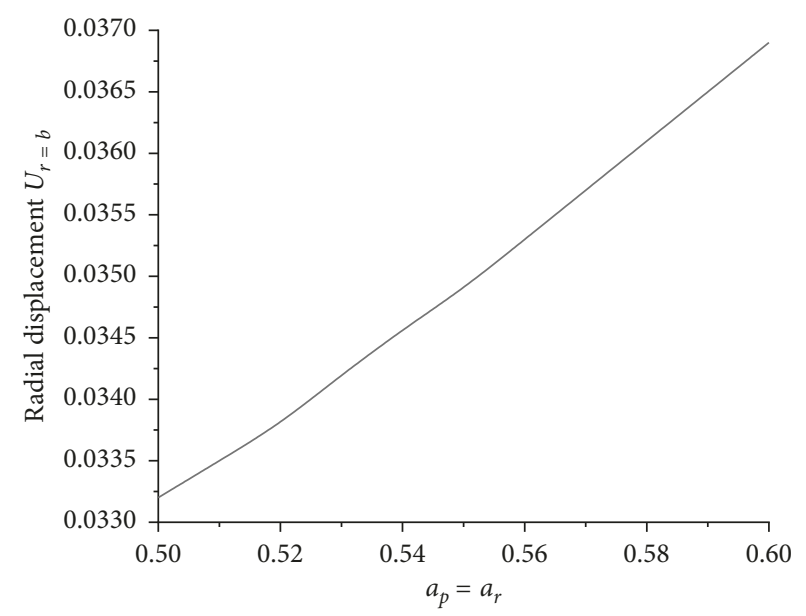

FIgURE 27: Variation of radial displacements on the opening surface with the change of parameter $a$ considering seepage force.

will become more obvious when the support pressure $p_{i}$ is lower; that is, the influence of $a_{p}$ and $a_{r}$ on the solutions reduces with the growth of support pressure $p_{i}$, when considering seepage force.

From Figure 27, the strength parameters $a_{p}$ and $a_{r}$ have great influence on the displacement when considering seepage force. The radial displacement grows rapidly with the increase of $a_{p}$ and $a_{r}$. But the influence of $a_{p}$ and $a_{r}$ on the displacement when considering seepage force is weaker than that without considering seepage force.

\section{Conclusions}

A dimensionless approach is developed for elastoplastic analysis of circular opening excavated in a strain-softening rock mass based on the generalized Hoek-Brown and M-C failure criterion. The plastic zone is divided into a finite 
number of concentric rings in this study. In order to solve the equilibrium and compatibility equations for each ring, the dimensionless method is used for calculating the stresses and displacement in the strain-softening zone. Through analysis of examples, some conclusions can be drawn:

(1) As the number of annuli $n$ is sufficiently large $(n=500)$, the distribution of stresses and displacement of strain-soften rock mass obtained in this study show a good agreement with the existing solutions presented by Sharan [15] and Lee and Pietruszczak [21], which indicates that the dimensionless method developed in this study is reasonable and efficient.

(2) Five values of the deviatoric plastic shear strain $\gamma^{p *}$ analyzed in this study are $0,0.004,0.008,0.012$, and 100 . The plastic radius $R_{p}$ will reduce with the increase of deviatoric plastic shear strain $\gamma^{p *}$. When the deviatoric plastic shear strain is close to 0 , the obtained solutions have a good agreement with the brittle-plastic solutions. The largest plastic zone appears in the brittle-plastic case, and the thinnest plastic zone takes place for the case of elastic-perfectly plastic surrounding rock.

(3) The strength parameters $a_{p}$ and $a_{r}$ have an obvious influence on the dimensionless solutions. For $a_{p}=a_{r}$, the plastic radius $R_{p}$ grows with the increase of $a_{p}$ and $a_{r}$, which means the plastic zone becomes larger. When $a_{p}$ remains unchanged and $a_{r}$ becomes larger, the plastic radius will increase. In addition, the residual zone will increase with the increase of $a_{p}$ and $a_{r}$. The dimensionless displacement for $a_{p}=a_{r}=0.6$ is about 1.4 times larger than that for $a_{p}=a_{r}=0.5$. The plastic radius $R_{p}$ for $a_{p}=a_{r}=0.6$ is about 1.5 times larger than that for $a_{p}=a_{r}=0.5$. Furthermore, different values of $\sigma_{0}$ and $P_{0}$ have great impact on the dimensionless solutions under the generalized $\mathrm{H}-\mathrm{B}$ criterion. The radial displacement for brittle-plastic rock mass rapidly grows with $\sigma_{0}$ increasing and the radial displacement for elasticperfectly plastic behavior raises slowly, which reflects that $\sigma_{0}$ has great influence on dimensionless radial displacements when the deviatoric plastic shear strain $\gamma^{p *}$ becomes smaller. The radial displacement for brittle-plastic behavior gradually grows with the increase of $P_{0}$ and the radial displacement for elasticperfectly plastic behavior increases very slowly, which reflects that $P_{0}$ has little influence on dimensionless radial displacements when the deviatoric plastic shear strain $\gamma^{p *}$ becomes larger.

(4) For the analysis of a circular opening excavated in a strain-softening rock mass considering seepage force, the stresses are smaller but the plastic radius and radial displacement are larger than the results without considering seepage force, which reflects that the seepage force can increase the effective stresses around a circular tunnel. The deviatoric plastic shear strain $\gamma^{p *}$ has an obvious influence on the solutions when considering seepage force. The plastic radius $R_{p}$ will reduce with the increase of deviatoric plastic shear strain $\gamma^{p *}$. As the deviatoric plastic shear strain is close to 0 , the solutions finely match the brittle-plastic solutions. The largest plastic zone appears in the brittle-plastic case, and the thinnest plastic zone takes place for the case of elastic-perfectly plastic surrounding rock. Moreover, the strength parameters $a_{p}$ and $a_{r}$ have an obvious influence on the plastic radius $R_{p}$. The plastic radius grows with the increase of $a_{p}$ and $a_{r}$. But the plastic radius will decrease rapidly with the increase of support pressure $p_{i}$.

\section{Data Availability}

The datasets generated and analysed during the current study are available from the corresponding author on reasonable request.

\section{Conflicts of Interest}

The authors declare that they have no conflicts of interest.

\section{Acknowledgments}

This work was supported by National Key R\&D Program of China (2017YFB1201204).

\section{References}

[1] E. Alonso, L. R. Alejano, F. Varas, G. Fdez-Manin, and C. Carranza-Torres, "Ground response curves for rock masses exhibiting strain-softening behaviour," International Journal for Numerical and Analytical Methods in Geomechanics, vol. 27, no. 13, pp. 1153-1185, 2003.

[2] E. T. Brown, J. W. Bray, B. Ladanyi, and E. Hoek, "Ground response curves for rock tunnels," Journal of Geotechnical Engineering, vol. 109, no. 1, pp. 15-39, 1983.

[3] S. Wang, X. Yin, H. Tang, and X., "new approach for analyzing circular tunnel in strain-softening rock masses," International Journal of Rock Mechanics and Mining Sciences, vol. 47, no. 1, pp. 170-178, 2010.

[4] G. H. Chen, J. F. Zou, and Z. H. Qian, “An improved collapse analysis mechanism for the face stability of shield tunnel in layered soils," Geomechanics and Engineering, vol. 17, no. 1, pp. 97-107, 2019.

[5] J. F. Zou and P. H. Zhang, "Analytical model of fully grouted bolts in pull-out tests and in situ rock masses," International Journal of Rock Mechanics and Mining Sciences, vol. 113, no. 1, pp. 278-294, 2019.

[6] J. Zou, G. Chen, and Z. Qian, "Tunnel face stability in cohesion-frictional soils considering the soil arching effect by improved failure models," Computers and Geotechnics, vol. 106, pp. 1-17, 2019.

[7] J.-f. Zou, Z.-h. Qian, X.-h. Xiang, and G. H. Chen, "Face stability of a tunnel excavated in saturated nonhomogeneous soils," Tunnelling and Underground Space Technology, vol. 83, no. 1, pp. 1-17, 2019. 
[8] J.-F. Zou, A. Wei, and T. Yang, "Elasto-plastic solution for shallow tunnel in semi-infinite space," Applied Mathematical Modelling, vol. 64, no. 12, pp. 669-687, 2018.

[9] J. F. Zou, F. Wang, and A. Wei, "A semi-analytical solution for shallow tunnels with radius-iterative-approach in semiinfinite space," Applied Mathematical Modelling, 2019.

[10] J. F. Zou, K. F. Chen, and Q. J. Pan, "Influences of seepage force and out-of-plane stress on cavity contracting and tunnel opening," Geomechanics and Engineering, vol. 13, no. 6, pp. 907-928, 2017.

[11] C. Li, J. F. Zou, and A. S. G., "Closed-Form solution for undrained cavity expansion in anisotropic soil mass based on the spatially mobilized plane failure criterion," International Journal of Geomechanics, 2019.

[12] X.-L. Yang and J.-H. Yin, "Slope equivalent Mohr-Coulomb strength parameters for rock masses satisfying the HoekBrown criterion," Rock Mechanics and Rock Engineering, vol. 43, no. 4, pp. 505-511, 2010.

[13] K.-H. Park and Y.-J. Kim, "Analytical solution for a circular opening in an elastic-brittle-plastic rock," International Journal of Rock Mechanics and Mining Sciences, vol. 43, no. 4, pp. 616-622, 2006.

[14] K.-H. Park, B. Tontavanich, and J.-G. Lee, "A simple procedure for ground response curve of circular tunnel in elasticstrain softening rock masses," Tunnelling and Underground Space Technology, vol. 23, no. 2, pp. 151-159, 2008.

[15] S. K. Sharan, "Analytical solutions for stresses and displacements around a circular opening in a generalized HoekBrown rock," International Journal of Rock Mechanics and Mining Sciences, vol. 45, no. 1, pp. 78-85, 2008.

[16] Y. Wang, "Ground response of circular tunnel in poorly consolidated rock," Journal of Geotechnical Engineering, vol. 122, no. 9, pp. 703-708, 1996.

[17] J.-x. Han, S.-c. Li, S.-c. Li, and W.-m. Yang, "A procedure of strain-softening model for elasto-plastic analysis of a circular opening considering elasto-plastic coupling," Tunnelling and Underground Space Technology, vol. 37, no. 6, pp. 128-134, 2013.

[18] H. Zheng, D. F. Liu, C. F. Lee, and X. R. Ge, "Principle of analysis of brittle-plastic rock mass," International Journal of Solids and Structures, vol. 42, no. 1, pp. 139-158, 2005.

[19] S. Wang, H. Zheng, C. Li, and X. Ge, "A finite element implementation of strain-softening rock mass," International Journal of Rock Mechanics and Mining Sciences, vol. 48, no. 1, pp. 67-76, 2011.

[20] S. Wang, S. Yin, and Z. Wu, "Strain-softening analysis of a spherical cavity," International Journal for Numerical and Analytical Methods in Geomechanics, vol. 36, no. 2, pp. 182202, 2012.

[21] Y.-K. Lee and S. Pietruszczak, "A new numerical procedure for elasto-plastic analysis of a circular opening excavated in a strain-softening rock mass," Tunnelling and Underground Space Technology, vol. 23, no. 5, pp. 588-599, 2008.

[22] C. Carranza-Torres and C. Fairhurst, "The elasto-plastic response of underground excavations in rock masses that satisfy the Hoek-Brown failure criterion," International Journal of Rock Mechanics and Mining Sciences, vol. 36, no. 6, pp. 777-809, 1999.

[23] A. Fahimifar and M. R. Zareifard, "A new closed-form solution for analysis of unlined pressure tunnels under seepage forces," International Journal for Numerical and Analytical Methods in Geomechanics, vol. 37, no. 11, pp. 1591-1613, 2013.

[24] Z. L. Li, Q. W. Ren, and Y. H. Wang, "Elasto-plastic analytical solution of deep-buried circle tunnel considering fluid flow field," Chinese Journal of Rock Mechanics and Engineering, vol. 23, no. 8, pp. 1291-1295, 2004, in Chinese.

[25] X. L. Yang and Q. J. Pan, "Three dimensional seismic and static stability of rock slopes," Geomechanics and Engineering, vol. 8, no. 1, pp. 97-111, 2015.

[26] C. Carranza-Torres, "Elasto-plastic solution of tunnel problems using the generalized form of the Hoek-Brown failure criterion," International Journal of Rock Mechanics and Mining Sciences, vol. 41, no. 41, pp. 629-639, 2004. 


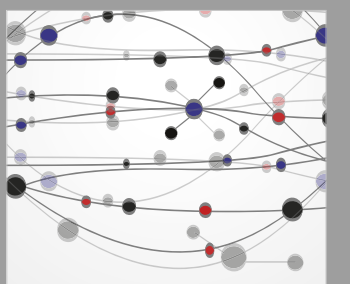

The Scientific World Journal
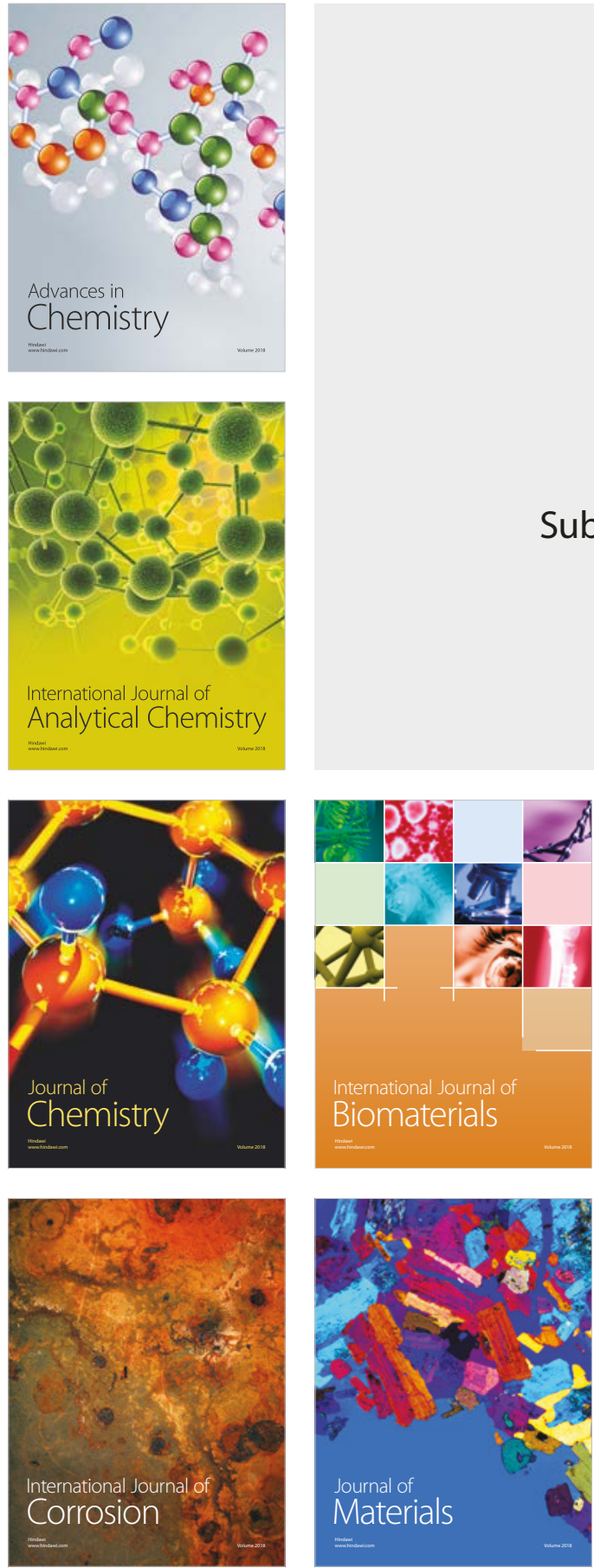

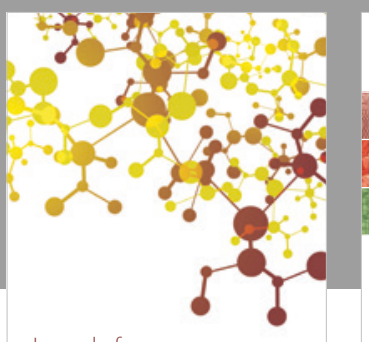

Journal of

Applied Chemistry
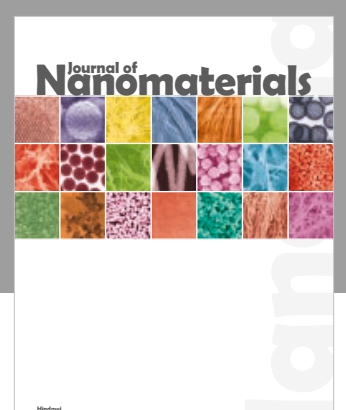

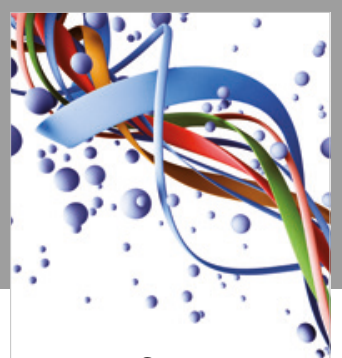

Scientifica

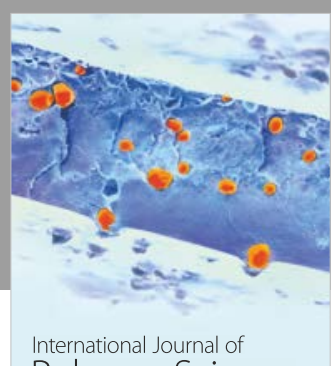

Polymer Science

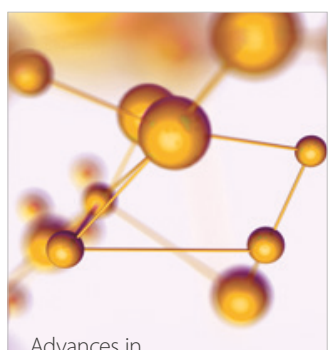

Physical Chemistry
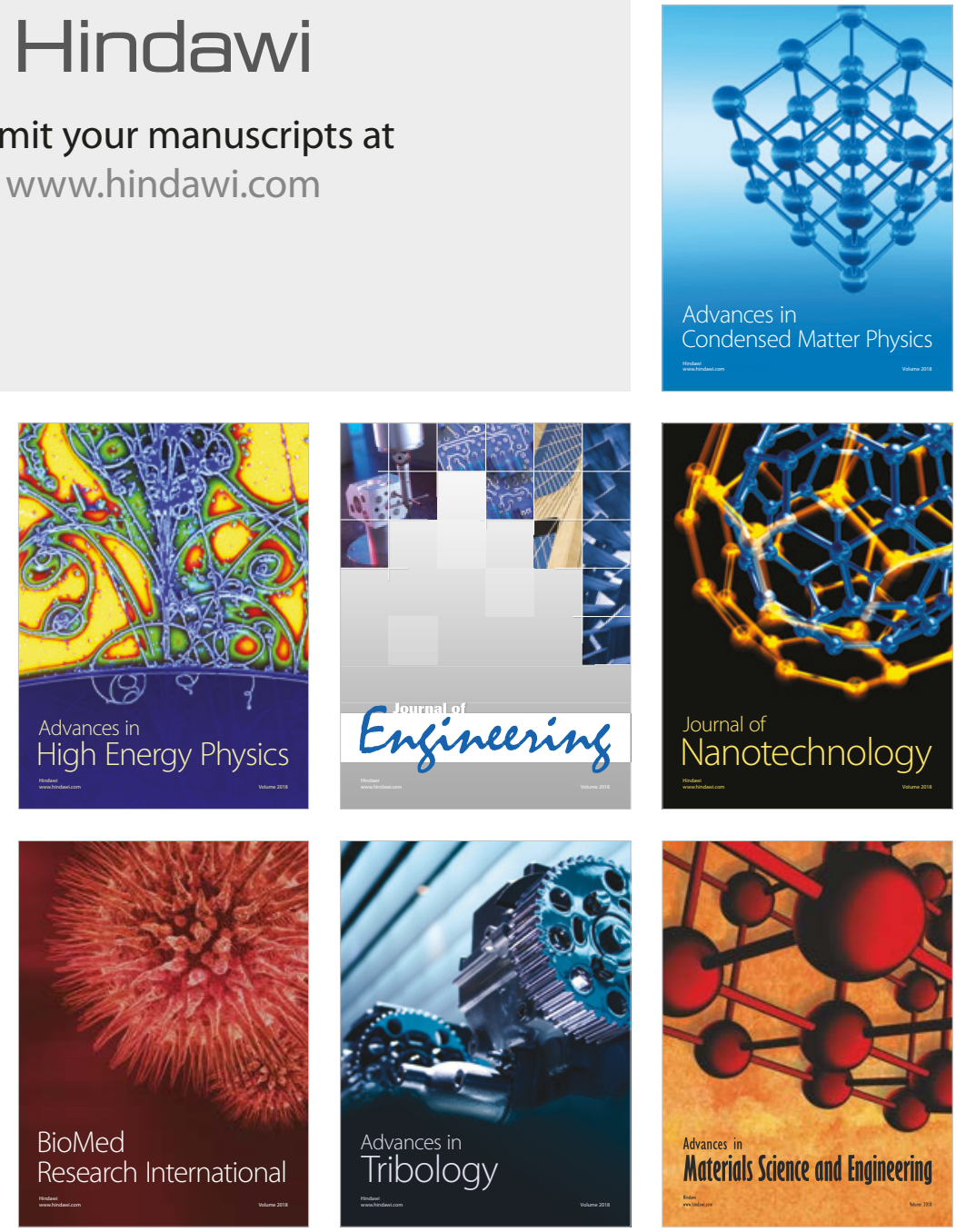